\title{
Observations of Diurnal Coastal-Trapped Waves with a Thermocline-Intensified Velocity Field
}

\author{
TAMARA L. SCHLOSSER AND NiCOLE L. JONES \\ Oceans Graduate School and the Ocean Institute, University of Western Australia, Crawley, Western Australia, Australia \\ Ruth C. Musgrave \\ Woods Hole Oceanographic Institution, Woods Hole, Massachusetts \\ CYNTHIA E. BLUTEAU \\ Institut des Sciences de la Mer, Universite du Quebec a Rimouski, Rimouski, Quebec, Canada \\ GREGORY N. IVEY \\ Oceans Graduate School and the Ocean Institute, University of Western Australia, Crawley, Western Australia, Australia \\ ANDREW J. LUCAS \\ Scripps Institution of Oceanography, University of California, San Diego, La Jolla, California
}

(Manuscript received 3 October 2018, in final form 1 May 2019)

\begin{abstract}
Using 18 days of field observations, we investigate the diurnal (D1) frequency wave dynamics on the Tasmanian eastern continental shelf. At this latitude, the D1 frequency is subinertial and separable from the highly energetic near-inertial motion. We use a linear coastal-trapped wave (CTW) solution with the observed background current, stratification, and shelf bathymetry to determine the modal structure of the first three resonant CTWs. We associate the observed D1 velocity with a superimposed mode-zero and mode-one CTW, with mode one dominating mode zero. Both the observed and mode-one D1 velocity was intensified near the thermocline, with stronger velocities occurring when the thermocline stratification was stronger and/ or the thermocline was deeper (up to the shelfbreak depth). The CTW modal structure and amplitude varied with the background stratification and alongshore current, with no spring-neap relationship evident for the observed 18 days. Within the surface and bottom Ekman layers on the shelf, the observed velocity phase changed in the cross-shelf and/or vertical directions, inconsistent with an alongshore propagating CTW. In the near-surface and near-bottom regions, the linear CTW solution also did not match the observed velocity, particularly within the bottom Ekman layer. Boundary layer processes were likely causing this observed inconsistency with linear CTW theory. As linear CTW solutions have an idealized representation of boundary dynamics, they should be cautiously applied on the shelf.
\end{abstract}

\section{Introduction}

The stratified continental shelf and slope support coastal-trapped waves (CTWs) with frequencies and spatial structures determined by the geometry, stratification, and wave frequency. The geometry of the continental shelf and slope and the vertical stratification

Corresponding author: Tamara Schlosser, tamara.schlosser@ research.uwa.edu.au give rise to natural frequencies of oscillation that, when coinciding with tidal frequencies, results in the amplification of tidal velocities on the shelf (Crawford and Thomson 1984). Subinertial CTWs are trapped to the continental shelf and slope, with velocities that exponentially decay with distance offshore (Huthnance 1978; Mysak 1980). Therefore, unlike freely propagating waves that can travel across shelves and oceans, CTWs must dissipate their energy near the shelf and slope and are thus a potential source of shelf mixing and mass transport. 
Subinertial CTWs have frequency $\omega$ less than the Coriolis frequency $f$, where at subinertial frequencies, trapped waves are the only wave type that can exist (Leblond and Mysak 1978). Subinertial CTWs coexist with superinertial freely propagating waves having $\omega>f$. Both subinertial and superinertial waves may have a combined effect on mixing near topography (Musgrave et al. 2016, 2017; Stashchuk and Vlasenko 2017; Waterhouse et al. 2017), with potential implications for the biological productivity of the shelf via enhanced fluxes of nutrients (e.g., Tanaka et al. 2013). However, as trapped waves are highly dependent on the characteristics of the topography and stratification (Huthnance 1978), the role of these waves in modifying mixing will vary by region and seasonally.

Huthnance (1978) explored the effect of stratification, as well as numerous other factors, on the velocity structure and propagation speeds of CTWs. He found that a strong and continuous stratification (i.e., no pycnocline) led to the formation of bottom-intensified velocities at the shelf edge, and Tanaka et al. (2013) found this resulted in enhanced fluxes of nutrients at the seabed in the southeastern Bering Sea. Observations from southeast Australia (Freeland 1988) and the Adriatic Sea (Mihanović et al. 2009) have captured diurnal CTWs with intensified velocity and temperature perturbations, respectively, within the pycnocline. The time series of Mihanović et al. (2009) show that the temperature perturbations within the pycnocline vary in magnitude as the pycnocline varies in depth. In summary, previous observations of CTWs suggest a dynamical dependence on the pycnocline depth and stratification, but this dependence is not well defined.

Here we use field observations to examine the vertical, temporal, and cross-shelf characteristics of subinertial CTWs at the diurnal (D1) frequency, on the density-stratified Tasmanian Eastern Continental Shelf (TECS). TECS is an ideal site to study CTWs as the frequency of the D1 tide $\left(7.27 \times 10^{-5} \mathrm{rad} \mathrm{s}^{-1}\right)$ is considerably smaller than $f\left(-9.64 \times 10^{-5} \mathrm{rad} \mathrm{s}^{-1}\right)$. We use the linear CTW solution of Brink (2006), which includes realistic topography, stratification, and background current, to help interpret the field observations. Using both observations and the CTW solution, we explore the sensitivity of these D1 CTWs to temporally varying background stratification and current. The observed D1 CTWs had intensified velocities within the thermocline, and we explore the dynamics controlling the magnitude of these intensified velocities. The observed D1 velocity was inconsistent with linear CTW theory within the surface and bottom Ekman layers, and we explore the possible causes. We last consider whether a CTW with thermocline-intensified velocities is likely to cause irreversible mixing.

\section{Coastal-trapped wave theory}

The spatial structure of CTWs depends on the continental shelf and slope geometry, the stratification, and the wave frequency (Mysak 1980). An unstratified and sloping shelf supports continental shelf waves, while a stratified shelf of constant depth and with a vertical shelf break supports internal Kelvin waves (Gill 1982). Both wave types are trapped to the coastal region, with typical cross-shore length scales on the order of the Rossby radius (Ro), where $\mathrm{Ro}=N h / f, N$ is the maximum buoyancy frequency, and $h$ is the local water depth. These trapped waves propagate with the coast on their left in the Southern Hemisphere. Shelf regions that are both stratified and depth-varying support a hybrid of these two wave types and are termed as CTWs.

The CTW modal structure has cross-shelf, along-shelf, and vertical dimensions and is highly dependent on the strength of the stratification relative to the width and depth of the shelf (Huthnance 1978). The influence of stratification can be approximated via the Burger number $S$, where $S=N H / f L, H$ is the deep-sea depth, and $L$ is the width of the shelf and slope. For very large $S$, CTWs tend to resemble internal Kelvin waves with vertical motion suppressed by the strong stratification. For intermediate $S$, the motion of fluid up- and downslope is inhibited and becomes confined to the bottom boundary, like the bottom-trapped waves shown by Rhines (1970). For small $S$ (i.e., weak stratification or at shallower depths), CTWs behave like unstratified modes (Crawford and Thomson 1984). For typical oceanic stratification, CTWs tend to have bottom-intensified velocities near the shelf break (except for the limiting case of small $N$ ) (Crawford and Thomson 1984). A realistic shelf with a background current and stratification that varies slowly over time will thereby have CTWs with modal structures and frequencies that also vary in time and across seasons.

For the case of uniform alongshore bathymetry, CTWs are wavelike in the alongshore direction and decay in the offshore direction (e.g., Crawford and Thomson 1984). The CTW structure then has dimensions in the cross-shore and vertical directions only. Using a linear CTW solution, the dispersion relation and modal structure of CTWs with variable cross-shelf bottom slope and stratification can thus be determined. We use the linear CTW solution of Brink (2006), as it allows a free surface and the inclusion of an alongshore background current, so that we can resolve modes zero and higher with the observed background conditions. 
The Brink (2006) solution approximates the equations of motion as linear, hydrostatic, Boussinesq, and in an $f$ plane, as follows:

$$
\begin{aligned}
\frac{\partial v}{\partial t}+u \frac{\partial v_{g}}{\partial x}+v_{g} \frac{\partial v}{\partial y}+w \frac{\partial v_{g}}{\partial z}+f u & =-\frac{1}{\rho_{0}} \frac{\partial p}{\partial y}, \\
\frac{\partial u}{\partial t}+v_{g} \frac{\partial u}{\partial y}-f v & =-\frac{1}{\rho_{0}} \frac{\partial p}{\partial x}, \\
0 & =-\frac{\partial p}{\partial z}-g \rho, \\
\frac{\partial u}{\partial x}+\frac{\partial v}{\partial y}+\frac{\partial w}{\partial z} & =0, \\
\frac{\partial \rho}{\partial t}+u \frac{\partial \rho_{g}}{\partial x}+v_{g} \frac{\partial \rho}{\partial y}+w \frac{\partial \rho_{g}}{\partial z} & =0,
\end{aligned}
$$

where $u(x, y, z, t), v(x, y, z, t)$, and $w(x, y, z, t)$ are the perturbation velocities in the cross-shore $(x)$, alongshore $(y)$, and vertical $(z)$ directions, respectively; $p(x, y, z, t)$ is the pressure perturbation; and the total density is the sum of the density perturbation $\rho(x, y, z, t)$, the reference density $\rho_{0}$, and the geostrophic density $\rho_{g}(x, z)$. Components describing geostrophically balanced quantities are denoted with a subscript $g$, where $v_{g}$ is in balance with $p_{g}$ and $\rho_{0}+\rho_{g}$.

The CTW solution assumes pressure has the form

$$
p(x, y, z, t)=p(x, z) \exp [i(\omega t+k y)],
$$

where both $\omega$ and the alongshore wavenumber $k$ are real. The problem is then reduced to the following single partial differential equation for pressure,

$$
\begin{aligned}
0= & \omega^{\prime} \frac{\partial^{2} p}{\partial x^{2}}-2 \omega^{\prime} s \frac{\partial p}{\partial x} \frac{\partial p}{\partial z}+\omega^{\prime} N^{-2}\left(f f^{\prime}-\omega^{2}\right) \frac{\partial^{2} p}{\partial z^{2}}-\omega^{\prime}\left(Q+\frac{\partial s}{\partial z}\right) \frac{\partial p}{\partial x} \\
& -\left[-\omega^{\prime} s Q+\frac{\partial\left(\omega^{\prime} s\right)}{\partial x}+k f^{-1} s\left(f^{2}-\omega^{2}\right)-\frac{\partial\left(\omega^{\prime} N^{-2}\right)}{\partial z}\left(f f^{\prime}-\omega^{\prime 2}\right)-\left(\omega^{\prime} N^{-2}\right) \frac{\partial\left(s M^{2}\right)}{\partial z}\right] \frac{\partial p}{\partial z} \\
& -\left(k f Q+\omega^{\prime} k^{2}+k f \frac{\partial s}{\partial z}\right) p,
\end{aligned}
$$

where the following variables are defined,

$$
\begin{aligned}
N^{2} & =-\frac{g}{\rho_{0}} \frac{\partial \rho_{g}}{\partial z}, \\
M^{2} & =-\frac{g}{\rho_{0}} \frac{\partial \rho_{g}}{\partial x}, \\
\omega^{\prime} & =\omega+k v_{g}, \\
s & =\frac{M^{2}}{N^{2}}, \\
f^{\prime} & =f+\frac{\partial v_{g}}{\partial x}, \\
f^{*} & =f+\frac{\partial v_{g}}{\partial x}-M^{2} \frac{s}{f}, \quad \text { and } \\
Q & =\left(f f^{*}-\omega^{\prime 2}\right)^{-1}\left[\frac{\partial\left(f f^{*}-\omega^{\prime 2}\right)}{\partial x}-s \frac{\partial\left(f f^{*}-\omega^{\prime 2}\right)}{\partial z}\right] .
\end{aligned}
$$

At the boundaries, we apply a linearized free surface,

$$
w=\left(g \rho_{0}\right)^{-1}\left(\frac{\partial p}{\partial t}+v_{g} \frac{\partial p}{\partial y}\right), \quad \text { at } \quad z=0,
$$

and no flow through the bottom,

$$
0=w+u \frac{\partial h}{\partial x}, \quad \text { at } \quad z=-h(x),
$$

where $h(x)$ is the seabed depth. There is no flow through the coastal boundary,

$$
u=0, \quad \text { at } \quad x=0,
$$

and the signal decays away from the coast,

$$
\frac{\partial u}{\partial x}=0, \quad \text { at } \quad x=x_{M},
$$

where $x_{M}$ is the maximum extent of the cross-shelf domain.

Realistic bathymetry, stratification, and a background current can be represented in the Brink (2006) linear solution. The solution is forced by a pressure force at the surface, offshore of the shelf break, with a defined frequency $\omega$ and alongshore wavenumber $k$. The resulting CTW pressure field is then determined, which has a corresponding $\omega$ and $k$. If this CTW is resonant with the shelf and slope topography and stratification, the resulting CTW pressure will be amplified. Hence, resonant 

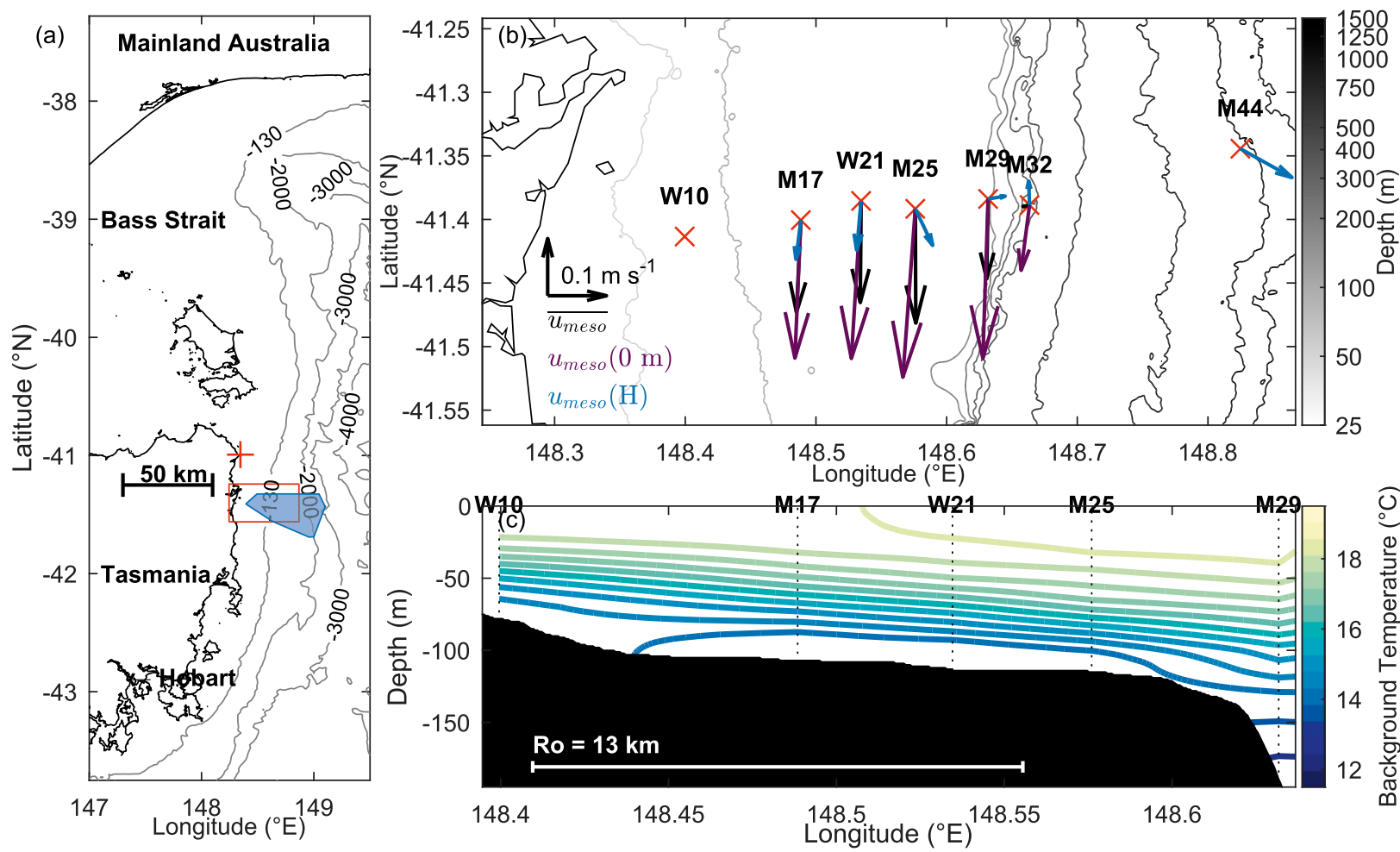

FIG. 1. (a) The island of Tasmania and mainland Australia, with our study area (red square), the bathymetry (gray contours), the ship location (shaded blue region), and Larapuna Bureau of Meteorology wind station (red plus). (b) Mooring positions (red crosses) with local bathymetry and the full-depth (black arrow), near-surface (purple arrow), and near-seabed (blue arrow) mean 40-h low-pass filtered (i.e., mesoscale) current at moorings with working ADCPs. (c) The time-mean mesoscale temperature at all shelf moorings. We indicate the mode-one internal Rossby radius $\left(\mathrm{Ro}_{n=1}\right)$.

CTW modes are identified by solving for the induced pressure to find which values of $\omega$ and $k$ correspond to large increases in pressure. The CTW cross-shore and alongshore velocity is then determined from the CTW pressure, using the reorganized equations of motion. For example, if there was no background current (i.e., $v_{g}=0$ ), the cross-shore velocity is calculated via

$$
u=\frac{i}{1-\omega^{2} / f^{2}}\left(\frac{\omega \partial p}{f \partial x}-k p\right)
$$

Here we use the simplified version of the Brink (2006) linear solution, called BIGR, which does not include bottom friction and assumes modes are stable (i.e., neither decay nor grow over time) (Brink 2018). The full version of the CTW solution, called BIGC, includes bottom friction as an infinitesimally thin bottom boundary, which accurately reduces the predicted velocity of CTWs in nearshore waters with depths $<50 \mathrm{~m}$. However, our testing indicated that this thin layer does not result in any change in the modal structure of CTWs away from the nearshore region and does not reproduce a realistic bottom boundary (e.g., Brink and Lentz 2010).

\section{Methodology}

\section{a. Study site}

Our study site was located at $41.4^{\circ} \mathrm{S}$ on the TECS, where the shelf is $\sim 28 \mathrm{~km}$ wide. The inner $12 \mathrm{~km}$ of the shelf is relatively steep $\left(0.25^{\circ}-1^{\circ}\right.$ slope $)$, while the midshelf is relatively flat $\left(<0.25^{\circ}\right.$ slope $)$ before sharply steepening to $3^{\circ}$ at the shelf break and $>4^{\circ}$ on the continental slope (Fig. 1). The continental slope is orientated approximately north-south, deviating from true north by $3^{\circ}$ to the east. During the austral summer months, the southward-flowing East Australian Current Extension (EACE) commonly extends to approximately $42^{\circ} \mathrm{S}$ (Ridgway 2007). The EACE lies on the shelf and transports warm and salty tropical water south from northeast Australia to the cooler Tasman Sea (Cresswell 2000). An undercurrent transports sub-Antarctic water northward but is intermittent in the summer months (Oliver et al. 2016).

The TECS experiences relatively weak surface tides with strong and variable winds. The surface spring-tide range is around $1.4 \mathrm{~m}$ (i.e., microtidal). The austral summer winds since 2010 (from the Bureau of Meteorology's 
Larapuna station) were predominantly toward the north or south, but were strong and variable with a 50th and 95th percentile wind stress (speed) of $0.052 \mathrm{~N} \mathrm{~m}^{-2}$ $\left(5.5 \mathrm{~m} \mathrm{~s}^{-1}\right)$ and $0.23 \mathrm{~N} \mathrm{~m}^{-2}\left(11.6 \mathrm{~m} \mathrm{~s}^{-1}\right)$, respectively. In the open ocean, a low-mode internal tide beam at the semidiurnal (M2) frequency is generated at Macquarie Ridge south of New Zealand (approximately $1500 \mathrm{~km}$ southeast of our sampled transect), and propagates northwestward to the Tasman continental slope (Simmons et al. 2004; Boettger et al. 2015; Johnston and Rudnick 2015; Waterhouse et al. 2018). It is estimated that around $65 \%$ of the energy is reflected at the Tasmanian continental slope, and up to $30 \%$ propagates along-slope as a superinertial partially trapped wave (Klymak et al. 2016).

\section{b. Field experiment}

In February 2015, we measured physical and biological variables from moored and ship-based platforms on the TECS (Fig. 1b). In total, six moorings were deployed for 18 days along a cross-shelf transect from 5 to 24 February 2015 (yeardays 36-55), although we only show data from five moorings here. Throughout the manuscript, time is in UTC +0 , where the local time was UTC +11 . We deployed traditional moorings, autonomous profilers (Wirewalkers), and bottom-lander frames (Table 1). We named our moorings with a letter to designate the type of mooring ( $\mathrm{M}$ for traditional mooring or $\mathrm{W}$ for profiler) and a number to designate its distance from the shoreline in kilometers. Bottommounted acoustic Doppler current profilers (ADCP, Teledyne RD Instruments) were deployed near the two autonomous profilers ( $\sim 300 \mathrm{~m}$ away); however, the bottom-mounted ADCP near W10 was too tilted to be useful, and therefore we do not report this data.

Ship-based measurements included repeated casts with a conductivity-temperature-depth (CTD) sensor over a $20 \mathrm{~h}$ period at the M29 site with 68 casts in total, and we profiled three times with the CTD at each of the other two traditional moorings. These observations formed a subset of a larger field program, the Tasman Tidal Dissipation Experiment (T-TIDE), which measured $\mathrm{M}_{2}$ tidal energetics in the vicinity (Pinkel et al. 2015). We utilize the nearby T-TIDE moorings T4 and $\mathrm{T} 3$ that we rename to M32 and M44, respectively, for consistency. The M44 mooring did not sample the upper $550 \mathrm{~m}$ of the 1216-m-deep water column. Hence, through moored and ship-based observations we present highresolution velocity and/or temperature measurements at five distinct sites across the 28 -km-wide shelf and from two sites on the continental slope.

Each traditional mooring had one near-bottom upward looking ADCP, vertically distributed temperature loggers and one CTD. The ADCP at M17 stopped on yearday 51, four days prior to the other ADCPs. The autonomous profilers were equipped with profiling Seabird 52 CTD sensors (Rainville and Pinkel 2001; Pinkel et al. 2011). Both profilers sampled between $0.5 \mathrm{~m}$ below the water surface to 0.5 and $7.6 \mathrm{~m}$ above the seabed at W10 and W21, respectively. We only used data collected during the upward movement of the profilers, which had a median upward speed of $0.35 \mathrm{~m} \mathrm{~s}^{-1}$. To estimate water density at the traditional moorings, we used CTD measurements (from the autonomous profilers and ship) to derive a temperature-density relationship $\rho=1028.7-0.167 \times T$, where $\rho$ and $T$ were the water density $\left(\mathrm{kg} \mathrm{m}^{-3}\right)$ and temperature $\left({ }^{\circ} \mathrm{C}\right)$, respectively. We observed a single water mass with highly correlated temperature and density, with a correlation coefficient of 0.99 . The fastest measuring thermistors $(0.5 \mathrm{~s})$ on the traditional moorings were downsampled to the same interval $(10 \mathrm{~s})$ as the slowest sampling thermistors.

The raw ADCP velocities were quality controlled based on beam correlations, a fish detection algorithm, and via the Goring and Nikora (2002) despiking method. Velocities with low beam correlations were removed and a three-beam solution attempted. We then averaged the velocities over 2 min with a minimum proportion of good values of $25 \%$ at M29, which had a low proportion of scatterers, and $12.5 \%$ at all other moorings. The quality-controlled velocities had a data return ranging from $96 \%$ at M25 to $99 \%$ at M17.

\section{c. Data analysis}

\section{1) VeLOCITY DECOMPOSITION}

We separated the total observed velocity into the mesoscale, tidal, and inertial frequency velocity. We determined the mesoscale velocity $\mathbf{u}_{\text {meso }}(z, t)$ by low-pass filtering the raw velocity $\mathbf{U}(z, t)$ with the PL66 filter, a modified version of the PL64 filter that minimizes highfrequency side lobes (Alessi et al. 1985), using a 40-h cutoff period. To separate the tidal frequencies and the inertial period of $18.1 \mathrm{~h}$, we performed a time-varying harmonic fit on $\mathbf{U}(z, t)-\mathbf{u}_{\text {meso }}(z, t)$ at the diurnal (D1), semidiurnal (D2), and inertial frequencies. We performed individual fits on 3-day-long segments that overlapped with start times offset by $1 \mathrm{~h}$. The minimum frequency difference $\Delta \omega$ was $1 / 3$ day $^{-1}$, so while we could still separate the tidal species and the inertial frequency that have a minimum $\Delta \omega$ of approximately $1 / 3 \mathrm{day}^{-1}$, we could not separate the individual tidal constituents from each other (e.g., $\mathrm{S}_{2}$ and $\mathrm{M}_{2}$ ). Therefore, the major tidal frequencies were grouped as D1 (1 cycle per day) and D2 (2 cycles per day).

We derived a signal-to-noise ratio for all time segments from the harmonic fit and residual time series, discarded time segments with a signal-to-noise ratio of 


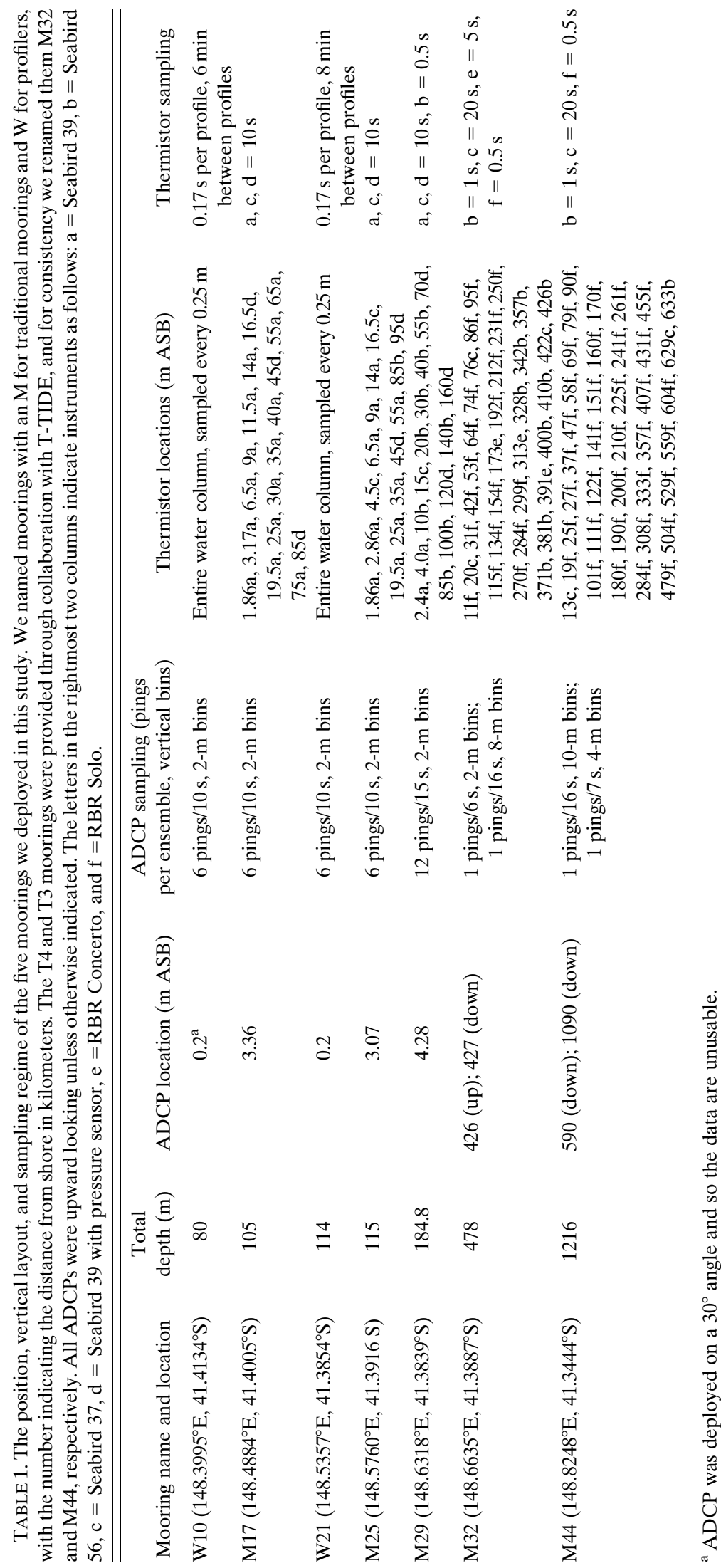


less than three, and ensemble-averaged the remaining overlapping time steps. Using longer segments than 3 days resulted in a lower return of statistically significant velocities, due to the observed variability in stratification over longer periods. By following these procedures, the tidal and inertial contributions were separated from each other over time and depth. Highly nonlinear internal waves were occasionally observed over the sample period at all moorings; however, as they were intermittent and did not have a consistent periodicity, their influence on our harmonic analysis procedure was minimal over the tidal and inertial frequencies investigated here (e.g., Shroyer et al. 2011).

\section{2) WIND STRESS}

We estimated the wind stress $\left(\mathrm{N} \mathrm{m}^{-2}\right)$ as

$$
\boldsymbol{\tau}_{w}(t)=C_{D} \rho_{A} \mathbf{v}(t)\|\mathbf{v}(t)\|,
$$

where $\mathbf{v}(t)$ is the ship-measured wind velocity, $C_{D}$ is the drag coefficient estimated as $1.4 \times 10^{-3}$ (Smith 1988), and $\rho_{A}$ is the air density estimated as $1.2 \mathrm{~kg} \mathrm{~m}^{-3}$. The location of the ship over the sample period is shown in Fig. 1a.

\section{3) ROTARY SPECTRA OF THE TOTAL VELOCITY}

We calculated rotary spectra $\hat{S}$ to determine the dominant rotation direction at each frequency from our velocity vectors. In the Southern Hemisphere, pure-inertial waves rotate counterclockwise (i.e., anticyclonically). Positive rotary frequencies correspond to the anticyclonic rotating spectra $\hat{S}^{+}$, while negative frequencies correspond to the cyclonic rotating spectra $\hat{S}^{-}$. We estimated the relative magnitude of the anticyclonic and cyclonic spectra via the rotary coefficient $r$, where $r=\left(\hat{S}^{+}-\hat{S}^{-}\right) /\left(\hat{S}^{+}+\hat{S}^{-}\right)$. A value greater (less) than zero indicates anticyclonic (cyclonic) flow, while a value of zero indicates rectilinear flow. We applied the sine-multitaper window in the time domain with two Slepian tapers, which has improved frequency resolution over the frequency range of interest (Alford and Whitmont 2007; Rayson et al. 2015).

To investigate the direction of phase propagation, we identified the phase difference in the cross-shore and alongshore velocity. To consider cross-shelf phase propagation, we compared the velocity at the same depth at different mooring locations. To investigate vertical phase propagation, we compared the velocity observed at $90 \mathrm{~m}$ depth to the velocity observed at other depths at the same mooring. We computed cross-spectra using the jLab software package (Lilly 2017), with the sinemultitaper window in the time domain. We removed frequencies with a coherence less than the confidence interval of $1-0.05^{1 /(2 P-2)}$, where $P$ is the number of
Slepian tapers, which we increased to three for the crossspectra analysis. We then focused on the phase differences within $\pm 10 \%$ of the D1 frequency, which we averaged to find the phase difference near the D1 frequency.

\section{Observations}

\section{a. Background conditions}

During the experiment, the predominantly southward flowing EACE was an energetic feature of the shelf oceanography. The depth-averaged mesoscale current reached $0.37 \mathrm{~m} \mathrm{~s}^{-1}$ and averaged $0.16 \mathrm{~m} \mathrm{~s}^{-1}$ over the shelf (Fig. 1b). The near-surface waters flowed south at an average of $0.25 \mathrm{~m} \mathrm{~s}^{-1}$ on the shelf. The near-seabed current flowed south at $0.09 \mathrm{~m} \mathrm{~s}^{-1}$ on average but flowed north at M29. For the first 12 days (before yearday 50), we generally observed the maximum near-surface current at or between M25 and M29 (Fig. 2c). For the next 6 days (after day 50), the current moved onshore and was largest at W21 (there were no observations at M17 at this time). In summary, the mesoscale current was always surface-intensified but was unsteady in terms of both its magnitude and position on the shelf over the 18-day sample period.

Our sampling period covered both neap (day 39 and 53) and spring tides (day 46) and multiple strong wind events (Figs. 2a,b). The four dominant tidal constituents, determined by harmonic analysis of the pressure measurements at W21 (bottom-mounted), were thesemidiurnal $\mathrm{M}_{2}$, the diurnal $\mathrm{K}_{1}$ and $\mathrm{O}_{1}$, and the semidiurnal $\mathrm{S}_{2}$, with surface elevations of $0.35,0.12,0.08$, and $0.07 \mathrm{~m}$, respectively. The ship-observed wind rotated anticyclonically with a 50th and 95th percentile wind stress (speed) of $0.095 \mathrm{~N} \mathrm{~m}^{-2}\left(7.5 \mathrm{~m} \mathrm{~s}^{-1}\right)$ and $0.22 \mathrm{~N} \mathrm{~m}^{-2}$ $\left(11.4 \mathrm{~m} \mathrm{~s}^{-1}\right)$, respectively (Fig. 2b). The wind stress neared the 95th percentile magnitude on day 42 and 54 , and westward winds with stress around the median magnitude persisted from day 43 to 45 .

The stratification was relatively strong at all moorings for most of the record, but we observed both shallowing and weakening of the thermocline at different times (Figs. 3g,h). The observed stratification can be characterized as a three-layer system with a well-mixed surface layer, a linearly stratified bottom layer, and a broad thermocline that shallowed at all moorings from day 39 to 51, with a change in thermocline depth from approximately 80 to $50 \mathrm{~m}$ depth at W21 (Fig. 3g). From day 51 , at all moorings, the thermocline sharply deepened within approximately a day, for example, to $80 \mathrm{~m}$ at W21. A second shallower layer of stratification then formed at $40 \mathrm{~m}$ depth at W21, while the original $80 \mathrm{~m}$ deep thermocline weakened over the remainder of the 

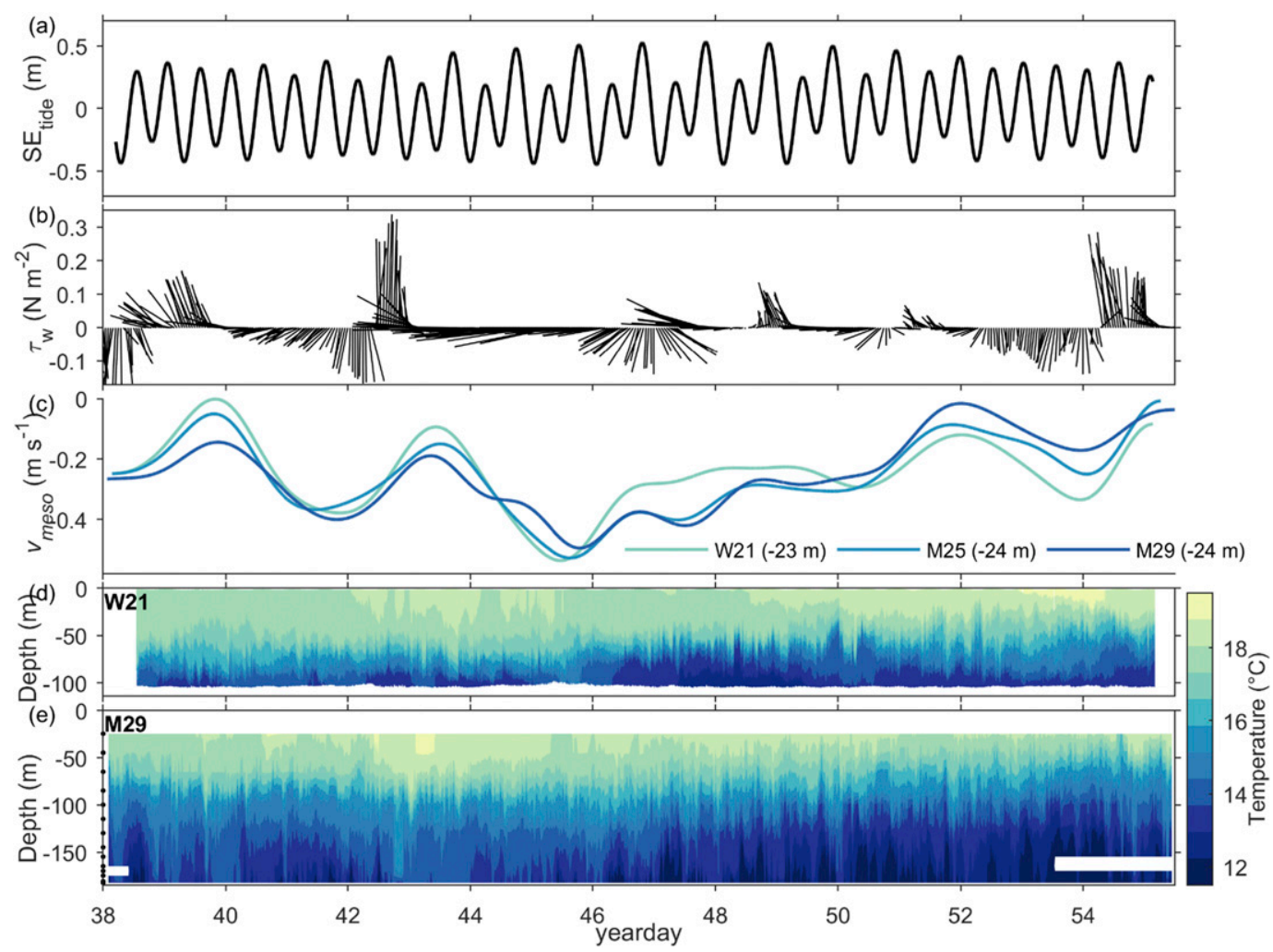

FIG. 2. (a) Tidal surface elevations from W21 (isolated with harmonic analysis at all tidal frequencies), (b) wind stress measured by the R/V Revelle and averaged over $2 \mathrm{~h}$, with the wind direction indicating the direction winds flow toward, (c) alongshore mesoscale current at 24-m depth at W21 to M29, and temperature at (d) W21 and (e) M29. The black markers in (e) show the thermistor locations on M29.

sample period. The stratification of the upper layer then exceeded the lower layer and thereby became the thermocline. The cross-shelf gradients in the EACE velocity and background density, combined with the background stratification, resulted in $f^{*} \neq f$ [Eq. (8f)]; however, $f^{*}>0.85 f$ for all times and depths, and hence was separated from the D1 frequency at $0.76 f$ [see Schlosser et al. (2018, manuscript submitted to J. Phys. Oceanogr.) for further details]. For the entire field campaign, the stratification was sufficient to support internal waves at near-inertial and tidal frequencies.

\section{b. Tidal and near-inertial waves}

Rotary spectra of the total velocity indicated significant D1, D2, and near-inertial peaks near the surface and only significant tidal peaks near the seabed (Figs. 4a,b). The D1 and near-inertial peaks were distinct, and thus the D1 frequency was subinertial. The near-inertial energy was anticyclonic and its variance decreased with depth at both W21 and M29 (Figs. 4c,d). The tidal frequencies had larger cyclonic variance than the nearinertial frequencies, but smaller anticyclonic variance at most depths (Fig. 4). The resulting rotary coefficient $r$ [section 3c(3)] at both W21 and M29 varied from -0.2 to 0.65 at the D2 frequency, from 0.2 to 0.85 at the D1 frequency, and from 0.4 to 1 at the inertial frequency (not shown), where a value of $1(-1)$ represents anticyclonic (cyclonic) flow in perfect circles. Hence, motion at the inertial and D1 frequencies was anticyclonic, while motion at the D2 frequency varied in rotation direction over the water column.

We considered the temporally varying tidal and nearinertial motion by implementing a sliding harmonic fit to isolate the three frequencies of interest. The resulting velocity magnitudes (i.e., $\sqrt{u^{2}+v^{2}}$ ) at the inertial frequency indicated that in addition to the surfaceintensified velocity that the rotary spectra described, the velocity was also large at depth for periods of approximately 3 days (Figs. 3c,d). The tidal and inertial velocity magnitudes were comparable; however, the D2 velocity was overall smaller (Fig. 3). The inertial and D1 velocity magnitudes were similar near the surface, both tidal frequencies and inertial velocity magnitudes were similar near the thermocline, and near the seabed, tidal velocity magnitudes exceeded inertial magnitudes. We focus on the highly energetic inertial velocity in a 

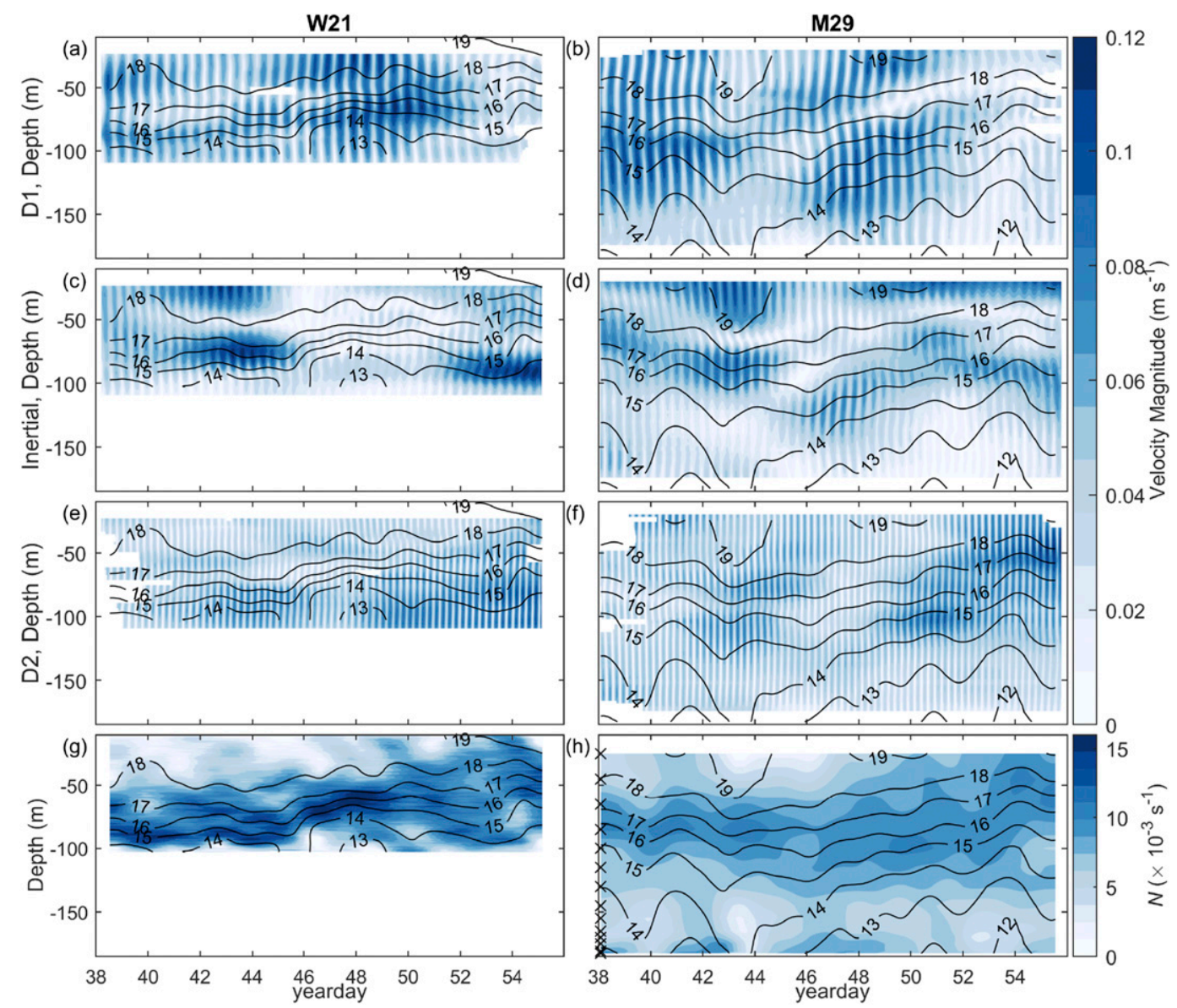

FIG. 3. Velocity magnitudes, isolated with the time-varying harmonic analysis, at (a),(b) D1; (c),(d) inertial; and (e),(f) D2 frequencies; and (g),(h) the mesoscale stratification $N$ at sites (left) W21 and (right) M29. We show the mesoscale temperature with isotherms $\left({ }^{\circ} \mathrm{C}\right)$ in black and the thermistor locations at M29 with black crosses in (h), which due to their sparsity in the mid- to upper water column, likely resulted in an underestimate of the stratification.

separate manuscript (Schlosser et al. 2018, manuscript submitted to J. Phys. Oceanogr.), and here we consider only the subinertial D1 motion.

We observed a large D1 frequency velocity near the thermocline that typically exceeded the magnitude of those at other depths (Figs. 3a,b and 5). The nearsurface velocity was not significantly coherent with the ship-observed wind at the D1 frequency (not shown), and therefore it was unlikely to have been driven by a D1 sea breeze. The D1 velocity at all depths was generally larger during spring tide (day 46) than neap tide (day 39 and 53), although we observed a large nearthermocline velocity during the first neap tide at M25 and M29 (Figs. 5e-h). The alongshore D1 velocity typically exceeded the cross-shore velocity at all moorings, with the median ratio of cross-shore to alongshore velocity amplitude (i.e., $\|u / v\|$ ) ranging from 0.38 at M17 to an average of 0.59 at all other moorings.
The along- and cross-shore velocity directions not only varied in their amplitude but also their velocity structure (Figs. 5 and 6). At the shallower M17 to M25 moorings, in the alongshore direction, the thermoclineintensified velocity was most evident before day 45 . From day 45 to 51, velocities increased at all depths so that there was minimal vertical gradient in velocity (i.e., $\partial \mathbf{u} / \partial z \approx 0$, Figs. 5 and $6 \mathrm{~b}$ ). In contrast, at M29 the alongshore velocity was more depth variable, with a minimum in velocity at approximately the $17.5^{\circ}$ isotherm, with the velocity also decreasing below the thermocline toward the seabed (Fig. 5h). The crossshore velocity was depth variable in its velocity structure at all moorings and all times (i.e., $\partial u / \partial z \neq 0$ ). The intensification of velocity near the thermocline was largest at M25 for the cross-shore velocity and was more consistent between moorings in the alongshore velocity direction. Overall, the variability in the observed D1 

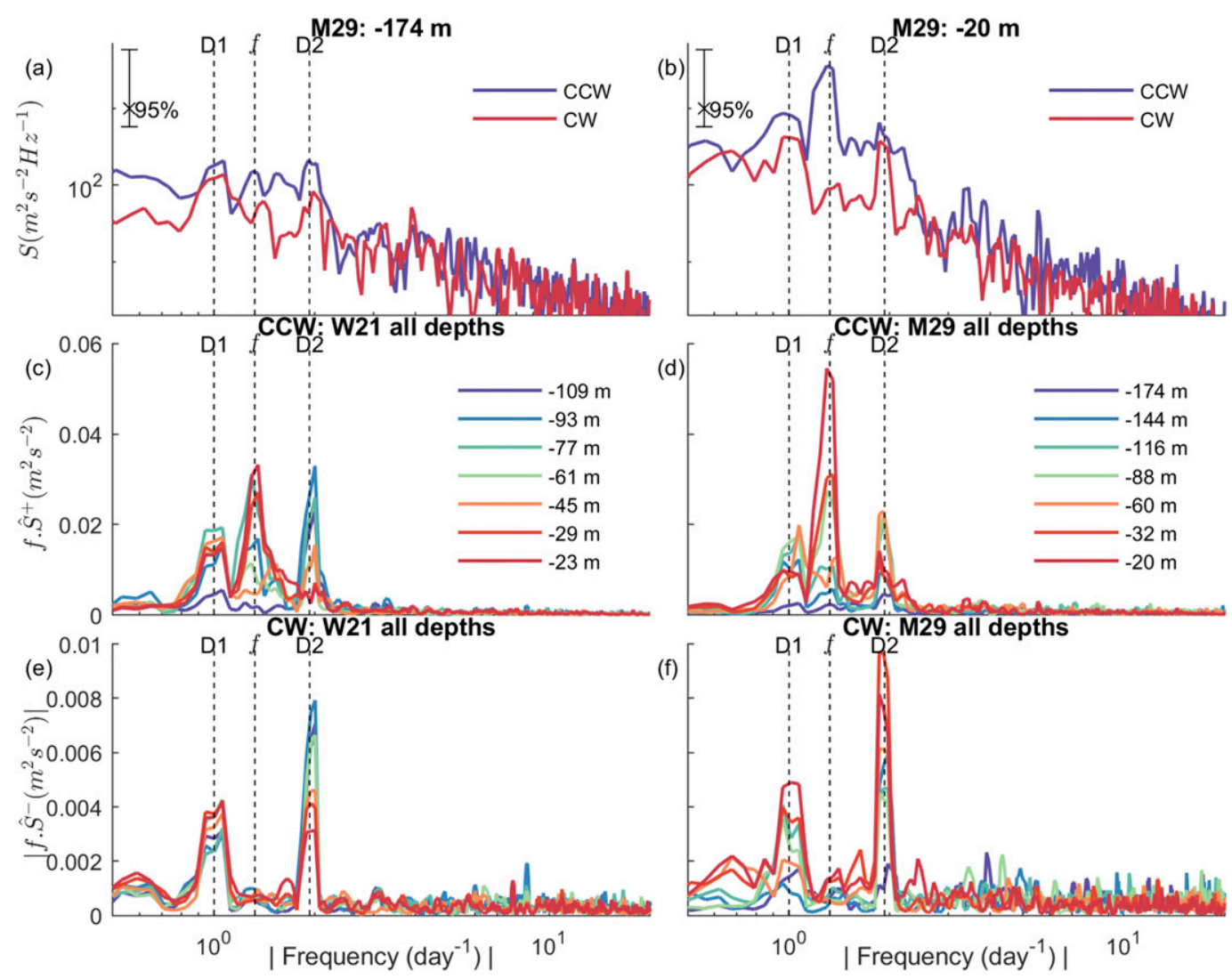

FIG. 4. Rotary spectra of the total velocity in log-log form for the anticyclonic (counterclockwise, blue) and cyclonic (clockwise, red) directions at M29 for the (a) near-seabed velocity and (b) near-surface velocity. We show variance-preserving spectra at (c),(e) W21 and (d),(f) M29 for seven equally spaced depths, for the anticyclonic direction in (c) and (d) and cyclonic direction in (e) and (f). Note (e) and (f) have smaller $y$ axis limits than (c) and (d).

velocity indicated that the wave field was varying in time, and the spatial structure of the velocity was varying with the local stratification and/or background current.

The phase of the cross-shore and alongshore D1 velocity was variable over depth but did not monotonically increase or decrease with depth over the full water column (Figs. 5 and 7a,c). At M17 to M25, the phase of the D1 cross-shore velocity decreased with depth below $90 \mathrm{~m}$, increased with depth above $90 \mathrm{~m}$ to a depth of $70 \mathrm{~m}$, generally decreased above $70 \mathrm{~m}$ at M17 and M25, but then increased above $50 \mathrm{~m}$ at M17. This vertical phase variability was consistent with downward phase propagation up to approximately $70 \mathrm{~m}$ depth. In contrast, at M29 the cross-shelf phase difference was minimal between 110 and $80 \mathrm{~m}$, where at shallower depths the crossshelf velocity was not significantly coherent and hence the phase difference was not resolved. In the alongshore velocity direction, the vertical phase difference was small at $<25^{\circ}$. Between 110 and $90 \mathrm{~m}$ depth and at M17 to M29, the vertical phase difference was consistent with downward phase propagation, but not at shallower depths. Within the upper $40 \mathrm{~m}$, the vertical phase difference became increasingly negative with distance offshore, consistent with increasing upward phase propagation with distance offshore.

The cross-shelf phase differences were even more variable over depth than the vertical phase differences (Figs. 5 and 7). For the cross-shelf velocity between 90 and $70 \mathrm{~m}, \mathrm{M} 25$ led both M29 and W21, while below $90 \mathrm{~m} \mathrm{M} 29$ led M25, M25 led W21, and W21 led M17. The phase variability below $90 \mathrm{~m}$ depth was consistent with friction acting first in shallower regions. For the alongshelf velocity and at all depths, W21 lagged both M17 and M25, and M29 led M25. The maximum cross-shelf phase differences of $4.4 \times 10^{-3 \circ} \mathrm{m}^{-1}$ corresponded to a $123^{\circ}$ phase difference if sustained across the entire $28 \mathrm{~km}$ wide shelf; however, comparisons between different moorings show that the phase difference was not sustained, except between 110 and $90 \mathrm{~m}$ depth (i.e., near the bottom boundary layer on the shelf) and in the crossshore velocity direction only. 

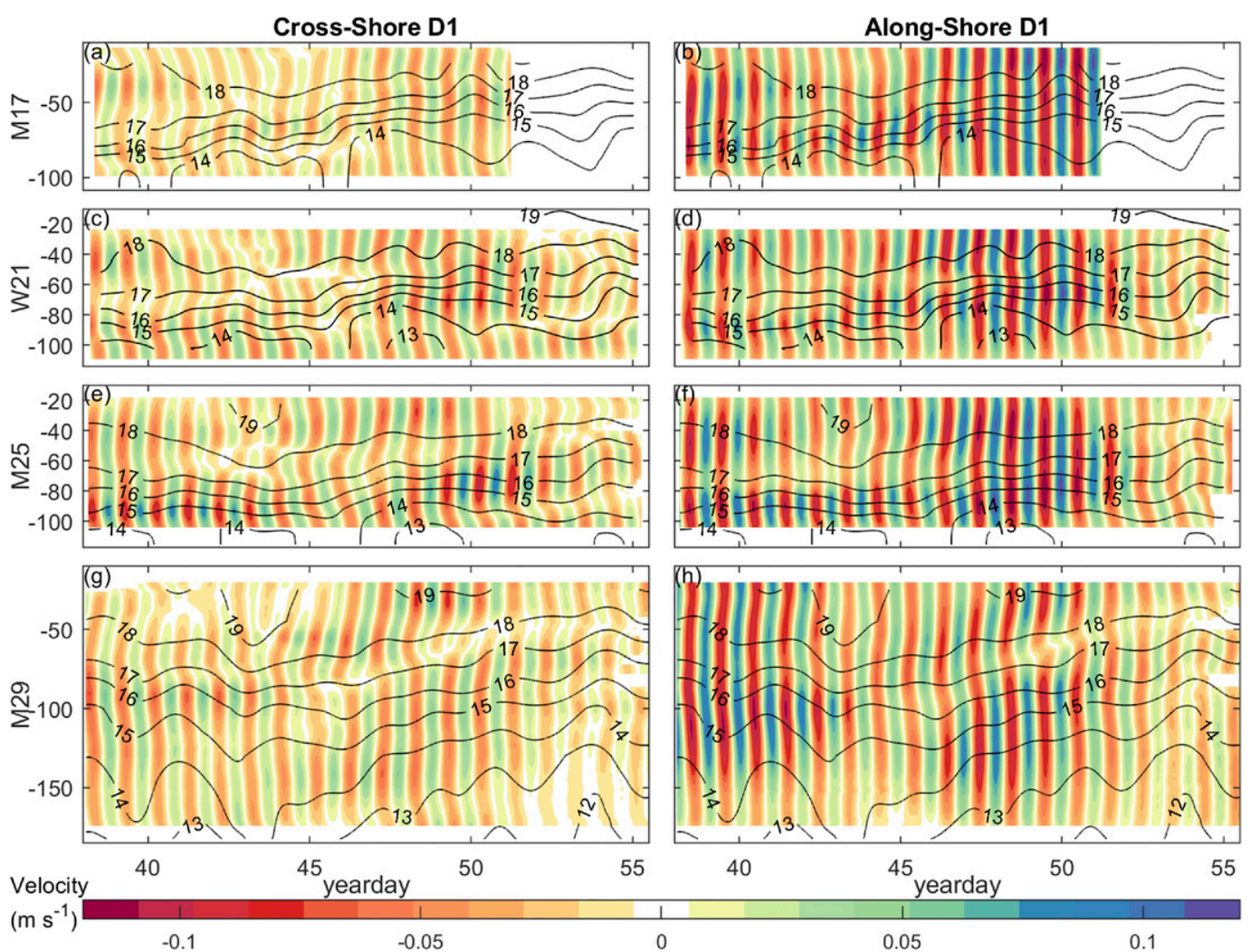

FIG. 5. The D1 (left) cross-shore and (right) alongshore velocity at moorings (a),(b) M17, (c),(d) W21, (e),(f) M25, and $(\mathrm{g}),(\mathrm{h}) \mathrm{M} 29$. The mesoscale temperature $\left({ }^{\circ} \mathrm{C}\right)$ is contoured in black.

The lack of a consistent monotonic increase or decrease in phase over most depths and the cross-shelf transect indicated minimal vertical and cross-shelf propagation was occurring, except near the surface and bottom boundary layers on the shelf. As vertical phase differences were monotonically increasing with depth only near the surface and bottom boundaries, non-wave-like and boundary processes may also be controlling the phase variability (e.g., Ekman veering), which we discuss further in section 6 .

\section{Linear CTW solutions}

At subinertial frequencies, the only wave type that can exist are trapped waves near topography and/or coastlines (Leblond and Mysak 1978). Using the linear CTW solution of Brink (2006) (see section 2) we looked for characteristics of the observed D1 velocity that were consistent with a CTW. As we observed changing background stratification and alongshore currents over time scales longer than a wave period, we ran the linear CTW solution with three setups of background stratification and/or currents that matched the observed conditions at different times. We then statistically compared the observed D1 velocity to multiple CTW modes and identified which mode(s) were present. We explored the dynamics controlling the modal structure of the CTW, which we relate to the observed D1 velocity. Although the linear CTW solution could replicate the observed D1 velocity structure offshore of the shelf break and in the midwater column on the shelf, near the upper and lower boundary layers on the shelf the linear CTW solution did not agree with observations. We discuss this divergence further in section 6.

\section{a. Setup}

We determined the dispersion curve for the first four CTW modes by iteratively searching for the wave frequency $\omega$ and alongshore wavenumber $k$ that resulted in a resonant response. We resolved only real $\omega$, but we confirmed all resonant modes had negligible imaginary $\omega$, indicating that the background current was baroclinically stable. The CTW solution employs a sigma grid, and we extended the domain to $200 \mathrm{~km}$ from the coast. We used 180 levels in the vertical to find dispersion curves, and 400 levels when comparing expected velocities from the CTW solution to observations. We kept the offshore depth at $4088 \mathrm{~m}$ for distances over 

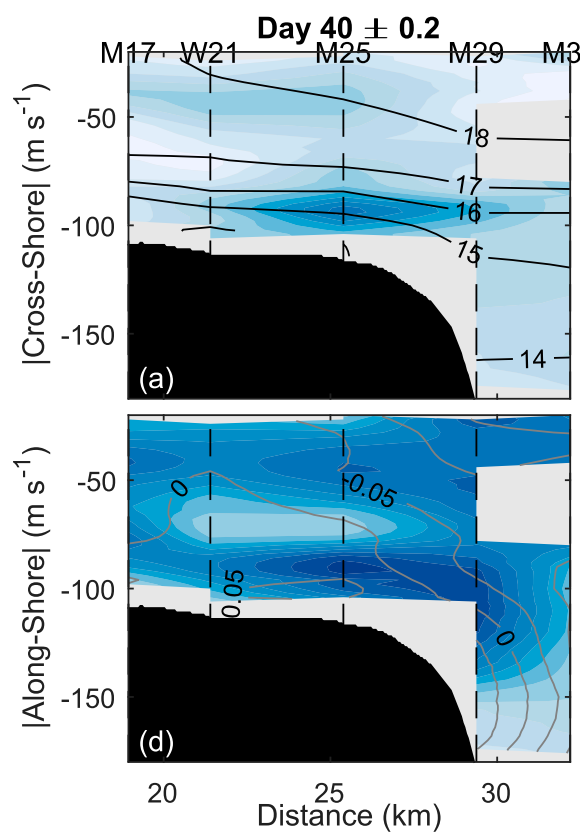

Day $48 \pm 0.2$
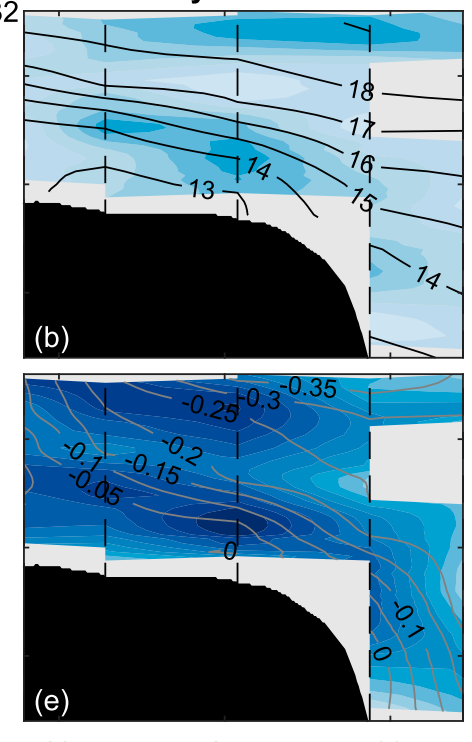

20
25
30

Distance

Day $52 \pm 0.2$

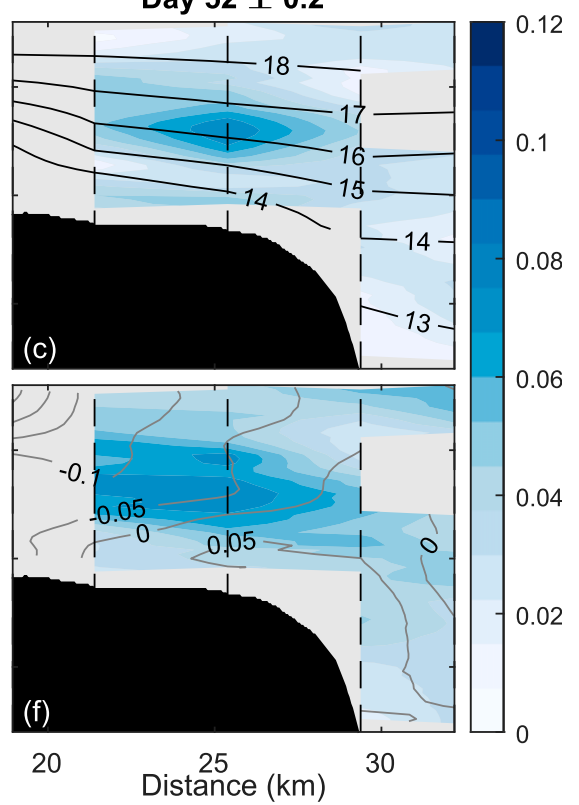

FIG. 6. The D1 velocity magnitude in the (top) cross-shore and (bottom) alongshore directions on day (UTC) (a),(d) 40; (b),(e) 48; and (c),(f) 52 . We show the maximum velocity magnitude within \pm 0.2 days of each day [i.e., the maximum cross-shore velocity between day 39.8 and 40.2 for (a)]. The mesoscale temperature is indicated with black isotherms $\left({ }^{\circ} \mathrm{C}\right)$ in (a)-(c), the mesoscale alongshore current with gray contours $\left(\mathrm{m} \mathrm{s}^{-1}\right)$ in (d)-(f), and the position of moorings with black dashed lines.

$92 \mathrm{~km}$ from the coast ( $660 \mathrm{~m}$ horizontal grid) and set a minimum depth of $2 \mathrm{~m}$. We removed topography (i.e., bumps) from the continental slope bathymetry by defining the slope as two points at 45 and $92 \mathrm{~km}$ from the coast, with a depth of 1172 and $4088 \mathrm{~m}$, respectively. The bathymetry between 0 and $45 \mathrm{~km}$ from the coast was unmodified. We used the local Coriolis frequency $f$ of $-9.64 \times 10^{-5} \mathrm{rads}^{-1}$, but due to horizontal and vertical gradients in the background current and stratification, the minimum wave frequency of freely propagating waves [Eq. (8f)] $f^{*}$ was $>0.85 f$. We set an accuracy for $\|\omega\|$ and $\|k\|$ of $0.01 \%$ when determining the dispersion curves in Fig. 8. When determining $k$ for the $\mathrm{K} 1$ frequency modes (with 400 vertical levels), we used a resolution of $0.5 \%$.

We used the observed mesoscale stratification and alongshore current in the CTW solution. We split the observational period into three segments during which the density and alongshore current were approximately steady: yearday $38-46,46-50$, and $50-56$. We estimated the alongshore geostrophic current $v_{g}$ on the shelf for each segment by applying a 3-day moving average to the alongshore mesoscale current $v_{\text {meso }}$ at all moorings, vertically smoothing with a $12 \mathrm{~m}$ moving average, and then averaging for each period. The CTW solution uses the thermal wind equation to determine the geostrophic density $\rho_{g}$ from the geostrophic current, using $f \partial v_{g} / \partial z=$ $-\left(g / \rho_{0}\right) \partial \rho_{g} / \partial x$. We ensured that the observed and mean density $\rho_{\text {ave }}$ matched the final background $\rho_{b}$ plus geostrophic density $\rho_{g}$ used by the solution by solving for $\rho_{b}$ in $\rho_{\text {ave }}=\rho_{g}+\rho_{b}$ at W21. To define $\rho_{\text {ave }}$, we applied a 3 -day moving average to the mesoscale density $\rho_{\text {meso }}$, then vertically smoothed with a $12 \mathrm{~m}$ moving average, before averaging observations over the three periods. We used this time-mean density $\rho_{\text {ave }}$ from W21 for the upper $90 \mathrm{~m}$, the observed density from T-TIDE CTD casts for the depth range $200-2000 \mathrm{~m}$, and shapepreserving piecewise interpolation for intermediate depth ranges. We then applied a 100-m moving average over the full depth. For the remaining $2000 \mathrm{~m}$, we exponentially reduced the deepest $N$ observation to a minimum of $5.0 \times 10^{-4} \mathrm{rad} \mathrm{s}^{-1}$.

\section{b. Evaluation}

To determine which CTW modes were present and their relative contribution to the observed velocity, we performed a least squares fit of the observed D1 velocity to the predicted modal structures, following a similar methodology to Cartwright et al. (1980). Our ability to distinguish modes depends on the placement of moorings with respect to the cross-shelf structure of the predicted modes. Though higher modes have more nodes, they are located offshore of the shelf break. Mode zero to two were close to barotropic over most of the shelf and had a nearly identical modal structure on the shelf (Fig. 9). As such, we use only M25 situated on the outer 

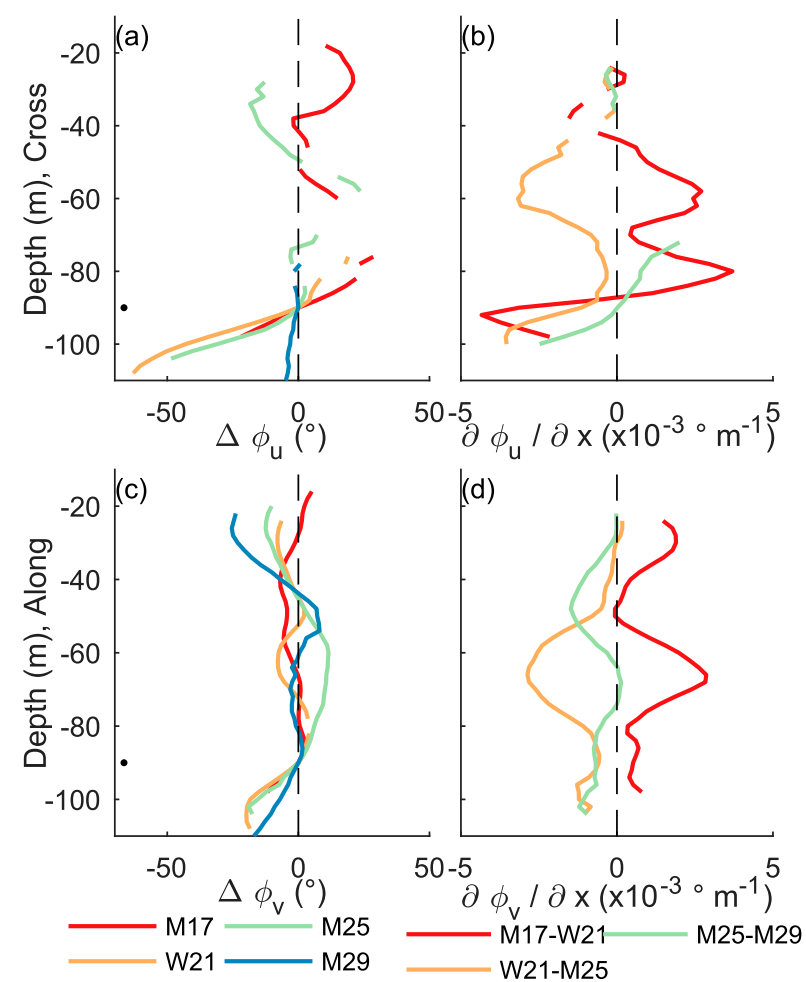

FIG. 7. The cross-spectra phase difference $\Delta \phi$ in the (a),(b) cross-shore and (c),(d) alongshore total velocity at the D1 frequency and for only depths where the coherence is significant. In (a) and (c) we compute the vertical phase difference along the same mooring line, with a reference depth of $90 \mathrm{~m}$ (black dot). Relative phase is positive when the currents at $z$ lead the currents at $90 \mathrm{~m}$. In (b) and (d) we compute the cross-shelf phase difference from nearby moorings at the same depth and then divide by the cross-shelf distance. Relative phase is positive when the currents at the onshore mooring lead the currents at the offshore mooring. We note both the expected mode-zero and mode-one CTWs have zero phase variability in the vertical and cross-shelf directions over the observed cross section of the shelf.

shelf (i.e., excluding M17 and W21), and M29 to M44 on the continental slope to perform the fits. We tested fitting with observations from all moorings and all depths and our conclusions remained the same. Fits were performed using the cross-shore $(u)$ and alongshore $(v)$ D1 velocity, as well the D1 induced pressure perturbation, defined as $p=\rho_{0} g \eta+\int_{-H}^{\eta} \rho_{\mathrm{D} 1} g d z$, where $g$ is the gravity constant, $\eta$ is the perturbation of the free surface $(\mathrm{m})$, $\rho_{\mathrm{D} 1}$ the D1 density perturbation, and we integrate from each depth between $-H$ and $\eta$ to $\eta$ (i.e., find the cumulative integral over depth). We did not accurately observe $\eta$ at all moorings, but at the two moorings where it was observed (W21 and the bottom lander frame near M29), $\eta$ was near identical. We hence used the observed $\eta$ at $\mathrm{W} 21$ for all moorings. We isolated the D1 frequency for $\rho_{\mathrm{D} 1}$ and $\eta$ with our sliding harmonic fit method described in section $3 \mathrm{c}(1)$.

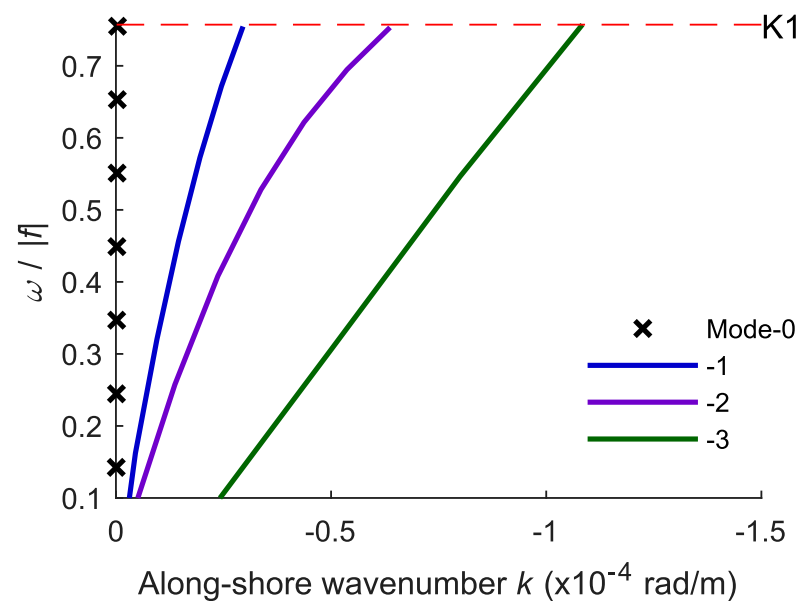

FIG. 8. The predicted dispersion curves for mode zero to mode three for a CTW solution setup with the average observed conditions on day 50-56. The wave frequency $\omega$ is scaled by $f$, we indicate the $\mathrm{K}_{1}$ frequency (red dashed line), and a negative alongshore wavenumber indicates a northward (equatorward) propagating wave for the TECS. As the dispersion curves reduced in accuracy with increasing proximity of the Doppler-shifted wave frequency $\omega^{\prime}$ to the resonant frequency $f^{\star}$ of $0.9 f$, we only show wave frequencies below the $\mathrm{K}_{1}$ frequency.

For each of the D1 variables considered $(u, v$, and $p)$, we found the observed amplitude $A_{j}(x, z)$ and phase $\phi_{j}(x, z)$ at M25 to M44 for the three periods (day 38-46, 46-50, and 50-56), and then defined the complex amplitude coefficient $Y_{j}(x, z)=A_{j}(x, z) / A_{j}^{*} \exp \left[i \phi_{j}(x, z)\right]$, where $A_{j}^{*}$ is the maximum of $A_{j}(x, z)$ and $j$ is $u, v$, or $p$. We then defined the complex amplitude coefficient from the predicted modal structures as $Y_{n, j}(x, z)=$ $A_{n, j}(x, z) / A_{j}^{*} \exp \left[i \phi_{n, j}(x, z)\right]$ for each of the three variables and periods (nine total), where $A_{n}$ is the amplitude and $\phi_{n}$ the phase of mode $n$. Note we apply the same scaling $\left(A^{*}\right)$ to both $Y(x, z)$ and $Y_{n}(x, z)$, for consistency. We then solved for the modal coefficient $b$ that is the same for every variable in:

$$
\begin{aligned}
\varepsilon= & {\left[Y_{u}(x, z)-\sum_{n=0}^{n_{m}} b_{n} Y_{n, u}\right]+\left[Y_{v}(x, z)-\sum_{n=0}^{n_{m}} b_{n} Y_{n, v}\right] } \\
& +\left[Y_{p}(x, z)-\sum_{n=0}^{n_{m}} b_{n} Y_{n, p}\right]
\end{aligned}
$$

such that the residual error $\varepsilon$ was minimized, where $n_{m}$ is the maximum number of modes used. We solved for $b$ using a variable number of CTW modes, to determine if including additional modes improved the fit of the summed modes to observations.

By including the phase in our fitting routine, we ensured fitted CTW modes propagate in the alongshore direction. Mode zero has $u 90^{\circ}$ out of phase with $v$ and $p$, 

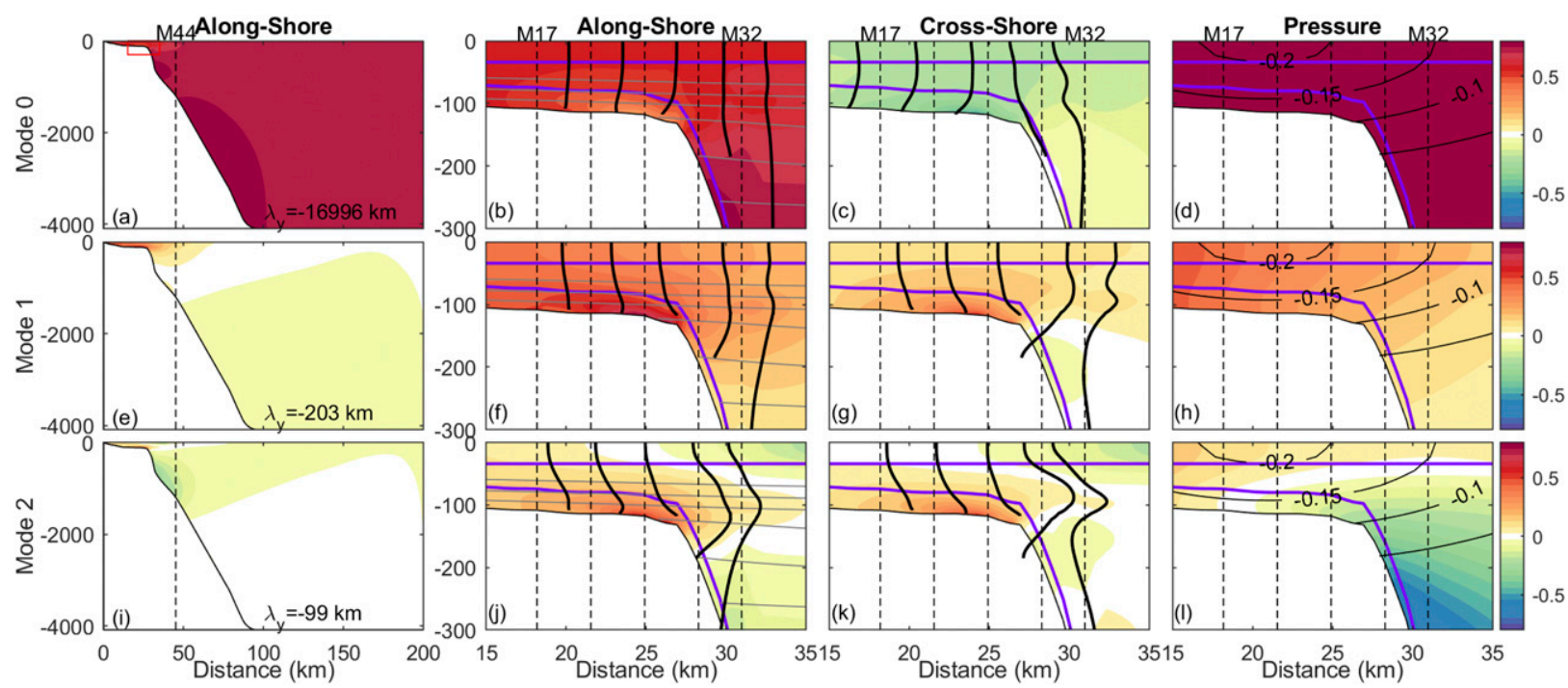

FIG. 9. The mode-zero to mode-two CTW velocity for the average background stratification $N$ and alongshore current $v_{g}$ observed during day 50-56. (a),(e),(i) The velocity in the alongshore direction over the entire domain of the CTW solution; over the shelf only [red square in panel (a)] we show the (b),(d),(f) along- and (c),(g),(k) cross-shore velocity, and (d),(h),(l) the pressure. Black dashed lines indicate the mooring locations, gray contours indicate the background density in the CTW solution, and black contours with labels indicate the specified $v_{g}$ in the CTW solution. We scaled the velocity of each mode by the maximum velocity magnitude (i.e., $\left.\sqrt{u^{2}+v^{2}}\right)$ in the CTW solution domain and scaled the pressure by the maximum pressure in the domain. The alongshore wavelength $\lambda_{y}$ of each mode is labeled in the left column. The bold black lines show the velocity structure of each mode in the vertical, at locations where we deployed moorings. Purple contours show the extent of the bottom and surface boundary layers that are excluded in the CTW fitting routine.

while all higher modes have $u-90^{\circ}$ out of phase with $v$ and $p$, consistent with cyclonic and anticyclonic motion, respectively. As $v$ and $p$ are in phase for all modes, their propagation direction is always alongshore and equatorward on the TECS. If the observed velocity and pressure have an inconsistent phase to the theoretical CTW modes, $\varepsilon$ will increase, resulting in a poorer fit to observations.

The linear CTW solution does not include friction when determining the modal structures and does not consider the effect of the Ekman layer at the surface or seabed (Brink 2006). For these reasons, we did not include the depth regions within the bottom and surface Ekman layers in the above fitting routine. We estimated the Ekman layer thickness using $d \approx(0.4 / f) \sqrt{\tau / \rho_{0}}$ (Cushman-Roisin and Jean-Marie 2011, chapter 8), where $\tau$ was the observed $\tau_{b}$ of $0.07 \mathrm{~N} \mathrm{~m}^{-2}$ determined from nearby measurements (Bluteau et al. 2016) for the bottom boundary and the observed $\boldsymbol{\tau}_{w}$ [Eq. (13)] for the surface boundary. The resulting bottom Ekman layer depth was $34 \mathrm{~m}$ for all three periods. The average surface Ekman layer depth was $42 \mathrm{~m}$ for day 38-46 and $34 \mathrm{~m}$ for the two periods following day 46. Together, the surface and seabed Ekman layers encompassed $58 \%-65 \%$ of the total water depth at M25 and $<9 \%$ of the total water depth at M32 (purple contour in Fig. 9).
We assessed the goodness-of-fit of the expected velocity and pressure from the CTW modes to the observed velocity and pressure for all three periods considered, and when a variable number of modes were included. We used the complex amplitude coefficient to reconstruct a time series for the wave, for example, $V(x, z, t)=\mathfrak{R}\left[Y_{v}(x, z) \exp (-i \omega t)\right]$, such that $t$ covers one wave cycle, and $\Re[\cdot]$ indicates we used the real part. Following this methodology, we ensured both the amplitude and phase of the observed D1 velocity and pressure were consistent with the linear CTW, which propagates northward on the TECS. To assess the performance of the solution in reproducing the observed velocity and pressure, we found the mean absolute error (MAE):

$$
\mathrm{MAE}=\frac{1}{m} \sum\left\|X_{\mathrm{obs}}-X_{\mathrm{mod}}\right\|,
$$

and the correlation coefficient (CC):

$$
\mathrm{CC}=\frac{1}{m} \frac{\sum\left(X_{\mathrm{obs}}-\overline{X_{\mathrm{obs}}}\right)\left(X_{\mathrm{mod}}-\overline{X_{\mathrm{mod}}}\right)}{\sigma_{\mathrm{obs}} \sigma_{\mathrm{mod}}},
$$

where $X_{\text {obs }}$ and $X_{\text {mod }}$ represent the discrete observed and expected variables from the CTW modes, respectively. The overbar denotes the mean of the variable, while $\sigma_{\text {obs }}$ and $\sigma_{\text {mod }}$ are the standard deviations of 

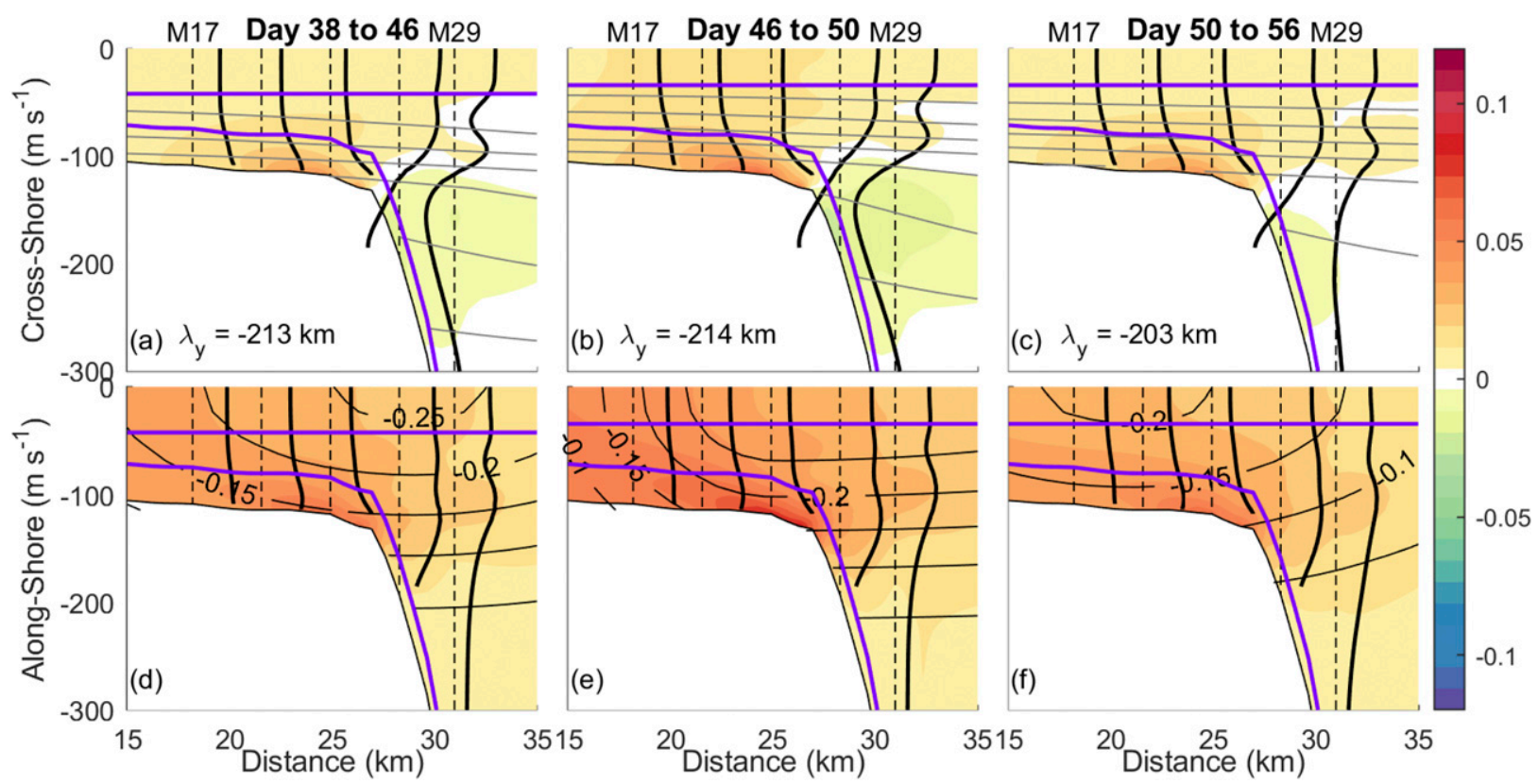

FIG. 10. The scaled mode-one CTW velocity $\left(\mathrm{m} \mathrm{s}^{-1}\right.$ ) in the (top) cross-shore and (bottom) alongshore direction, for day (a),(d) 38-46; (b),(e) 46-50; and (c),(f) 50-56 observed conditions. We scaled the mode-one velocity by least squares fitting both modes zero and one to the observed D1 velocity and determining the resulting scaling factor for mode one. Labels are consistent with Fig. 9.

$m$ number of observations (e.g., Murphy 1988; Rayson et al. 2015).

\section{c. Results}

We specified the observed background stratification and alongshore current in the CTW solution for three time periods: day $38-46,46-50$, and $50-56$, with the observed D1 velocity being largest during the second period that coincided with spring tide (Figs. 2a and 3a,b). We focus on the $K_{1}$ frequency, which had the largest D1 surface elevation at W21 (section 4a), but testing with the $\mathrm{O}_{1}$ tidal constituent produced identical modal velocities. We show the dispersion curve for the first four modes in Fig. 8 for the day 50 to 56 conditions. As mode one intersected $f$, all higher modes must intersect $f$ and the $K_{1}$ frequency (Huthnance 1978). However, as the Doppler-shifted wave frequency $\omega^{\prime}$ [Eq. (8f)] for mode three and higher exceeded $f^{*}$ at regions where the background current flowed southward (i.e., on the shelf), we cannot find solutions for these modes at the $\mathrm{K}_{1}$ frequency using this CTW solution. We demonstrate the validity of excluding these higher modes in the next section. We focus on the velocities on the continental shelf and the shelf break where we deployed moorings.

\section{1) Modal velocities}

We show the CTW modal velocity for day 50-56 conditions, for modes zero to two (Fig. 9), and we compare the mode-one velocity of each period (Fig. 10).
For mode zero, the velocity was primarily in the alongshore direction, and with each higher mode, the proportion of energy in the cross-shore direction increased. For all modes, there was a region of bottom-intensified velocity onshore of or at the shelf break and a thermocline-intensified velocity offshore of the shelf break, except for in the alongshore direction for mode zero (Fig. 9). The intensification of the velocity at the seabed and thermocline was larger for each higher mode. On the continental slope, the vertical structure of the velocity varied between each mode as the number of cross-shelf nodes increased. All modes had a similar cross-shore velocity structure over the relatively small cross section where the moorings were deployed, while the alongshore velocity was more variable in its velocity structure between modes, particularly at the deeper M29 and M32 moorings.

To assess the relative importance of the individual CTW modes, we fitted our summed modal velocity to the time-mean observations for each period and then assessed the goodness-of-fit using the two metrics described in section $5 \mathrm{~b}$. We present the metrics averaged across the three periods in Table 2, although overall there was minor variability between periods. In the alongshore direction, the CC improved with the addition of mode one but was similar if additional modes were included, or only mode zero and two were included. However, in the cross-shore direction, the CC improved with the addition of both mode one and two. The MAE 
TABLE 2. The CC and MAE resulting from fitting the observed and CTW modal D1 cross-shore velocity, alongshore velocity, and the pressure perturbation, at moorings M25 to M44, and for day 38-46, 46-50, and 50-56 separately, and then averaging the results of all periods. We included a variable number of modes when fitting to observations.

\begin{tabular}{|c|c|c|c|c|c|c|}
\hline \multirow[b]{2}{*}{ Mode $n$} & \multicolumn{3}{|c|}{$\mathrm{CC}$} & \multicolumn{3}{|c|}{ MAE } \\
\hline & Cross & Along & Pressure & Cross $\left(\mathrm{m} \mathrm{s}^{-1}\right)$ & Along $\left(\mathrm{m} \mathrm{s}^{-1}\right)$ & Pressure $(\mathrm{Pa})$ \\
\hline 0 & -0.17 & 0.59 & 0.94 & 0.02 & 0.03 & 251 \\
\hline $0-1$ & 0.59 & 0.89 & 0.94 & 0.02 & 0.02 & 263 \\
\hline $0-2$ & 0.69 & 0.88 & 0.94 & 0.01 & 0.02 & 264 \\
\hline 0,2 & 0.69 & 0.88 & 0.94 & 0.01 & 0.02 & 264 \\
\hline
\end{tabular}

slightly decreased when mode one was included for both velocity directions but increased for the pressure. In general, there was a minimal improvement if mode two was included, and by extrapolation, including higher modes (that we could not solve for) was unlikely to improve the fit to observations. We conclude that the observed CTW was described by mode zero and one, where on average across the three periods, mode zero contributed $6 \%$ and mode one $94 \%$ of the variance over our observational region in this two-mode solution.

The linear CTW solution predicted the velocity on the shelf was bottom-intensified, but we observed only a thermocline-intensified velocity. We excluded the bottom Ekman layer in our statistical comparison and obtained a high CC and low MAE, so in the midwater column on the shelf and throughout most of the water column offshore of the shelf break, the observed velocity and pressure were consistent with a linear modezero and mode-one CTW (Table 2). We discuss the performance of the linear CTW solution near boundaries in section 6 .

\section{2) TIME VARIABILITY}

We found the modal structure of the cross-shore and alongshore D1 velocity for day 38-46 and 46-50, which generally had a stronger background current and stratification than day 50-56 (Fig. 10). We estimate the influence of stratification and the topographic slope using $S=N H / f L$ (section 2), where $H$ was $4088 \mathrm{~m}, L$ was $90 \mathrm{~km}$, and $N$ was the maximum observed value for each of the three periods. The resulting $S$ varied from 5.3 for day $50-56$ to 6.5 for day $46-50$, and so remained in the intermediate range with $S>1$ but not $S^{-1 / 2} \ll 1$ (Huthnance 1978). As mode one accounted for approximately $94 \%$ of the observed velocity variance, we focused on the predicted changes in the mode-one structure due to varying stratification and background current (Fig. 10). In the alongshore direction, the main difference between periods was the horizontal and vertical extent of the bottom-intensified velocity and the relative magnitude of the thermocline-intensified velocity. This was also true for the cross-shore direction; however, in the cross-shore direction, the extent of opposing flowing waters between M29 and M32 also varied between periods.

To dissect the underlying cause of the change in D1 velocity structure for each period, we took the day 5056 case and modified the background stratification or alongshore current (Figs. 11 and 12). Increasing the stratification by $50 \%$ resulted in a larger vertical and horizontal (i.e., spatial) extent of the bottomintensified velocity in the alongshore direction and a larger thermocline-intensified velocity in both directions over a larger cross-shelf region (Figs. 11d and 12d). Removing the background current resulted in a similar effect, although the thermocline response was generally weaker, and there was a larger vertical extent of the bottom-intensified velocity in both directions (Figs. 11b and 12b). In contrast, increasing the alongshore background current by $50 \%$ decreased the spatial extent of the bottom-intensified alongshore velocity, and greatly increased the region of opposing cross-shelf velocity near M29 and M32 (Figs. 11e and 12e). The change in velocity structure due to an increase in the background current thereby led to a cross-shore velocity structure more similar to day 38-46 and 46-50, where the background current was larger during these periods (Figs. 10a,b).

As a final sensitivity test, we simultaneously removed the background current and altered the imposed stratification. We modified the stratification so that the thermocline was shallower or deeper than the observed range of thermocline depths of $50-80 \mathrm{~m}$ at W21. As the thermocline shallowed, the horizontal and vertical extent of the bottom-intensified D1 velocity increased, and the thermocline-intensified velocity decreased. In contrast, a deeper thermocline resulted in a more spatially confined bottom-intensified D1 velocity but a larger and more defined thermocline-intensified velocity. In summary, changes in the thermocline depth or stratification are predicted to lead to variations in the bottom versus thermocline velocity, with larger thermocline velocities for stronger stratification or a thermocline closer in proximity to the shelf break (Figs. 11 and 12). 

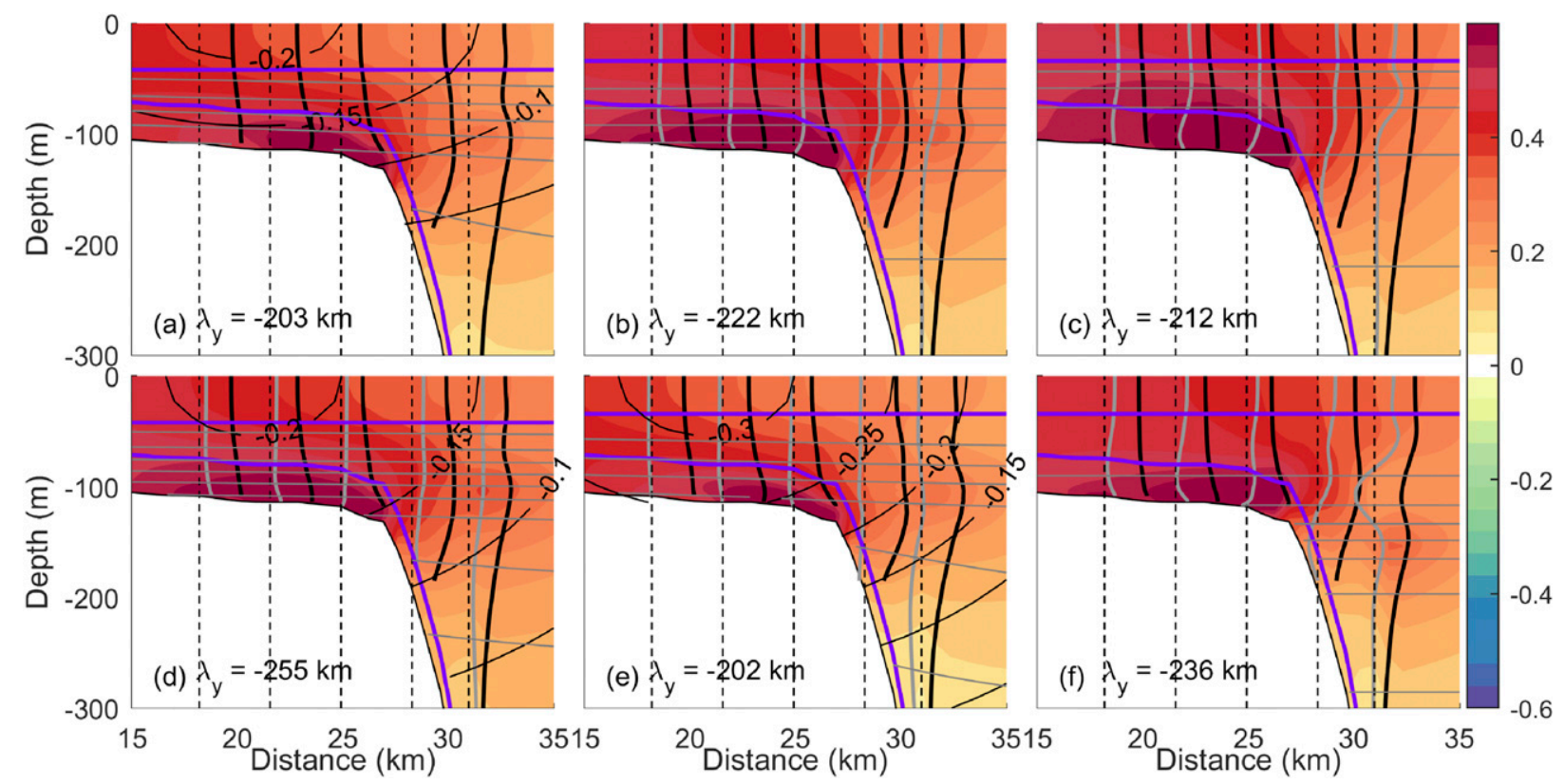

FIG. 11. (a) Predicted mode-one CTW alongshore velocity for six different scenarios, where the day 50-56 conditions were used, and we made the following modifications: (b) set $v_{g}=0$; (c),(f) set $v_{g}=0$ and set the thermocline in (c) $40 \mathrm{~m}$ shallower and in (f) $55 \mathrm{~m}$ deeper; (d) increased $N$ by $50 \%$; and (e) increased $v_{g}$ by $50 \%$. We ensured scenarios with modified $v_{g}$ had a background density matching the observed density $\rho_{\text {ave }}$ at W21, or $\rho_{\text {ave }}$ modified in depth for cases in (c) and (f), so that changes in the CTW solution setup were limited to only $v_{g}$, where possible. Labels are consistent with Fig. 10, but the additional gray contour at each mooring indicates the velocity shown in the panel, minus the unmodified day 50-56 velocity plotted in (a).

We generally observed larger velocities near the thermocline and over a larger cross-shelf region when the thermocline was deeper or had stronger stratification (Fig. 6), which agrees with the mode-one predictions (Figs. 11 and 12). Given the predicted changes in velocity structure for a larger background current, we expect the D1 shelf velocity would be weaker when the background current was larger (Figs. 11e and 12e). We observed the largest background current on day 45, which coincided with a reduction in the D1 velocity at moorings M25 to M32, where the reduction was largest at M29 (Figs. 3a,b and 5). However, the average background current was larger on days 46-50 than other times (i.e., days 38-46 and 50-56), and we observed the largest D1 velocity during this period (Fig. 6). On day 46-50, stratification was also stronger, which the CTW solution predicted would result in larger velocities on the shelf (Figs. 11d and 12d). The observed background current and stratification was on average weakest from day 50 to 56 , when we observed a reduction in the D1 velocity at all moorings (Fig. 6). This reduction in velocity was not consistent with the change in the modeone velocity structure when the background current was removed (Figs. 11a,b and 12a,b), particularly as the observed velocity also decreased at the deeper M32 mooring at all depths (Fig. 6).

\section{Discussion}

\section{a. Ekman layer motion}

The observed D1 velocity varied in phase in the crossshelf direction but did not monotonically increase or decrease at all depths (Fig. 7). We did observe sustained downward phase propagation within the bottom Ekman layer on the shelf for the cross-shore and alongshore velocity, and onshore phase propagation for only the crossshore velocity. These phase differences could indicate an upward and offshore freely propagating wave within the bottom Ekman layer of the shelf; however, given the D1 frequency was subinertial this was not possible. In the alongshore velocity direction, we observed upward phase propagation in the upper $40 \mathrm{~m}$ at all moorings except M17, where the phase difference increased in magnitude in the offshore direction (Fig. 7c). If this phase variability was directly forced by the local winds, M17 would also show upward phase propagation as wind-forced oscillations typically have lateral scales of O(10-100) km (e.g., Alford et al. 2016). Alternatively, the increasing upward phase propagation with distance offshore may be due to the surface-mixed layer also deepening with distance offshore (Fig. 1c) as an indirect consequence of the local wind forcing. In summary, within both the surface and bottom Ekman layer regions 


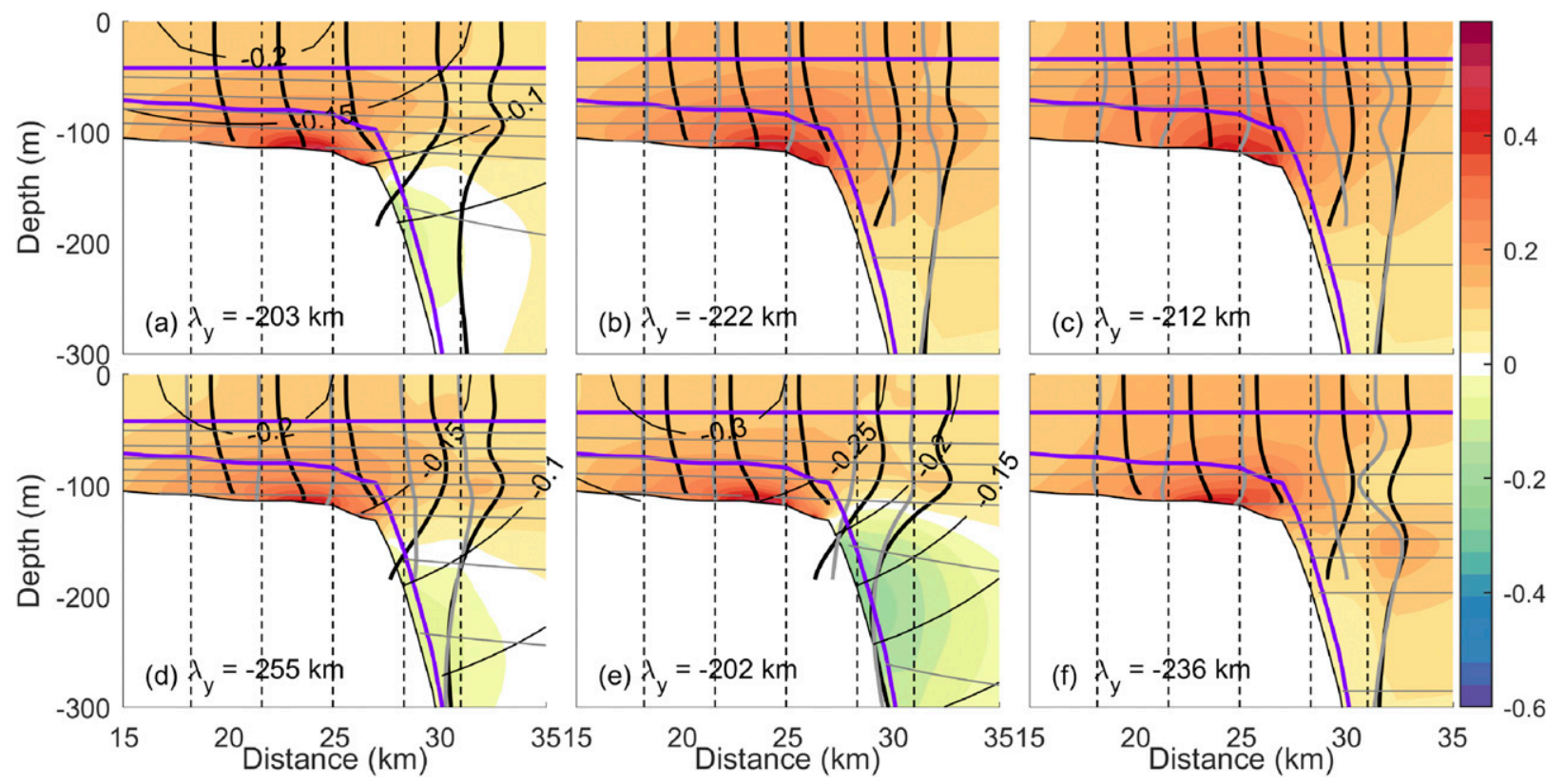

FIG. 12. As in Fig. 11, but for the cross-shore velocity.

of the shelf, we observed monotonically increasing or decreasing phase that was inconsistent with an alongshore propagating CTW.

On the other hand, comparing the observed D1 velocity and pressure field to a linear CTW solution we found an excellent agreement between observations and the CTW solution in the interior of the water column. This good agreement, the separation of the D1 and $f$ frequencies in the rotary spectra (Fig. 4), the local $f^{*}$ of $>0.85 f$ [Eq. (8f)], and the observed velocity phase throughout the mid water column (Figs. 5 and 7), all suggest that we observed a system dominated by D1 CTWs during our 18-day observation period.

It was not surprising that the CTW solution compared poorly with observations within the surface and bottom Ekman layer regions given the observed velocity phase variability in the vertical and cross-shelf directions. Boundary processes such as bottom friction, surface stress from the local winds, and Ekman veering complicate the dynamics within these boundaries (e.g., Brink and Lentz 2010). Anticyclonically rotating trapped wave motion with downward phase propagation has also been observed near other topography, such as seamounts (Codiga and Eriksen 1997), but the motion was bottomintensified while we observed bottom-reduced motion. Bottom-intensified CTW motion at the shelf break has also been shown in targeted laboratory experiments (Codiga et al. 1999), where motion at the shelf break was leading both onshore and offshore motion, due to bottom friction processes. We also observed near-seabed motion at the shelf break (M29) leading motion at more onshore moorings, but only for the cross-shelf velocity (Fig. 7b). Hence, our observed D1 velocity had vertical and cross-shelf differences in velocity phase that were consistent with other studies of near-seabed trapped wave motion affected by frictional processes; however, the relative magnitude of motion near versus above the seabed was opposite what was expected from these studies. We cannot further identify the cause of the reduced near-seabed velocities from our 18 days of observations, but the proximity of the thermocline, the background baroclinic current, the time variability in the background current and stratification, as well as other processes related to bottom friction, are all processes to consider. Given both our observations and other relevant studies (e.g., Codiga and Eriksen 1997; Codiga et al. 1999) show variability in the velocity phase in the vertical and cross-shelf directions, we recommend future studies utilizing linear CTW theory should exclude the Ekman layers when making comparisons to observations or nonlinear model results, as we have done here.

\section{b. Dynamics of D1 trapped waves}

We observed variations in the structure of the D1 velocity across the shelf and over depth for day 38-46, 46-50, and 50-56 that were overall consistent with the predicted change in CTW velocity structure due to varying stratification and/or background current (Figs. 6 and 10). The amplitude of the D1 velocity 
at all depths and cross-shelf locations also varied between periods, therefore, both the modal structure and amplitude of the D1 CTW changed between periods. The maximum velocity magnitude of the mode-zero D1 CTW where we deployed moorings, as found from our least squares fitting routine, was consistent for all periods at $0.01 \mathrm{~m} \mathrm{~s}^{-1}$. However, mode one varied from $0.08 \mathrm{~m} \mathrm{~s}^{-1}$ for day $38-46$ and day $50-56$ to $0.11 \mathrm{~m} \mathrm{~s}^{-1}$ for day $46-50$. We speculate that the observed variability in the D1 CTW amplitude was due to changes in the upstream generation of CTWs. Mihanović et al. (2009) observed D1 trapped waves over 6 months and identified a strong dependence of the trapped wave generation on the spring-neap cycle as well as the characteristics of the flow and stratification. Our observed D1 velocity did not strongly depend upon the spring-neap cycle over the sampled 18 days. We observed neap tide on day 39 and 53, and spring tide on day 46 (Fig. 2a). While we observed weaker D1 velocities on the second occurrence of a neap tide, we observed similar magnitudes of the D1 velocity on day 39 and 46 at M29 and slightly weaker D1 velocities on day 39 than day 46 at W21 (Figs. 3a,b). Overall, the observed D1 velocity was more consistent with changes in the characteristics of the flow and stratification than the spring-neap cycle.

An alternative cause of the reduced mode-one amplitude on day 50-56 was the concurrently observed reduction in stratification and magnitude of the background current, in addition to the current moving further onshore (Fig. 2c). The EACE extends to approximately $42^{\circ} \mathrm{S}$ in summer months (Ridgway 2007), $68 \mathrm{~km}$ south of our sampled transect, likely interacting with the D1 CTWs as they propagated from the south. From the rotary spectra of the observed total velocity, the EACE had an average periodicity in the current strength of approximately $38.5 \mathrm{~h}$ (Figs. 4e,f). The predicted mode-one CTW on day 50-56 had an alongshore wavelength $\lambda_{y}$ of $203 \mathrm{~km}$, and a group speed $c_{g}$ of $1.6 \mathrm{~m} \mathrm{~s}^{-1}$ near the D1 frequency (Fig. 8), so the D1 wave group would take approximately $35 \mathrm{~h}\left(\lambda_{y} / c_{g}\right)$ to propagate one wavelength. As the EACE varied over similar time scales, the generated D1 CTW may rapidly respond to variations in the EACE, and the EACE could directly influence the generation of D1 CTWs. We cannot further elucidate this relationship with our 18 days of observations, but our observations do suggest that the EACE may influence the generation of D1 CTWs in addition to influencing the velocity structure of D1 CTWs, which has been the focus of this manuscript.

Freeland (1988) observed D1 CTWs at three crossshelf transects off mainland Australia, where the D1 frequency is subinertial. Using a similar method to that employed here, they related their observed alongshore velocity to a mode-one CTW with an alongshore wavelength $\lambda_{y}$ varying between 250 and $370 \mathrm{~km}$ from their northern to southern transect, $9^{\circ}$ and $4^{\circ}$ north of our observed transect, respectively. Freeland (1988) exclude mode zero as the velocities were predicted to be small compared to mode one. While we do include mode zero here, we also found that the velocities associated with mode zero were an order of magnitude smaller than mode one. Our observed mode-one CTW had $\lambda_{y}$ that were more similar to the northern transect of Freeland (1988) than their closer southern transect, where our observed stratification was also more similar to the northern transect. The bathymetry of the middle transect was most similar to our observed transect, with the northern (southern) transect having a wider (thinner) shelf and a slightly steeper (much steeper) continental slope. At the northern transect, the mode-one CTW had a velocity structure comparable to the results presented here, with both bottom- and thermocline-intensified velocity. The CTW modes we identified, and their structure, are therefore consistent with those of Freeland (1988). We note that Freeland (1988) did not have current meters located in the region where the mode-one CTW had bottom-intensified currents. Mihanović et al. (2009) also observed D1 trapped waves when a thermocline was present, in the Adriatic Sea, and they observed large D1 isotherm perturbations within the thermocline. These isotherm perturbations were typically larger when the thermocline was deeper, so our finding of larger thermocline-intensified velocities when the thermocline was closer in proximity to the shelf break likely applies to other regions, including mainland Australia.

Between Tasmania and mainland Australia exists the Bass Strait with no continuous coastline (Fig. 1a). The 130-m isobath connects Tasmania with the mainland but undergoes a $90^{\circ}$ change in direction near the mainland from being aligned approximately north/south near Tasmania to east/west near the southeastern part of the mainland. Scattering of CTWs and a loss of CTW energy is dependent on the shelf width, the stratification, the length scale of the topographic irregularity, and the wave frequency and wavenumber (e.g., Wilkin and Chapman 1990; Codiga et al. 1999). While low-frequency $(\omega \ll$ 1 day $^{-1}$ ) and long-wavelength CTWs can propagate across the Bass Strait, Church and Freeland (1987) conclude that higher frequency $\left(\omega \approx 1\right.$ day $\left.^{-1}\right)$ CTWs are likely to dissipate as they propagate across the changing topography. The D1 CTWs we observed on TECS were likely generated south of our transect, and based on the findings of Church and Freeland (1987), they likely dissipated to the north, near or prior to reaching the Bass Strait. It is then likely that CTWs are 
generated at both Tasmania, which we observed, and mainland Australia (Freeland 1988), and we find they are comparable in the modes present and their velocity structure. The long-term ( $>6$ months) observations of Freeland (1988) and their agreement with our 18 days of observations reinforce that these waves are relevant over large regions and over long time scales, although our analysis highlights the temporal variability of CTWs over time scales longer than a wave period.

\section{c. Implications of D1 trapped waves}

Trapped waves have been found to enhance ocean mixing near topography at both local (e.g., Musgrave et al. 2017) and global scales (Falahat and Nycander 2015). On the continental shelf, CTWs are typically bottom intensified at the shelf break, except in the limiting case of weak stratification (Crawford and Thomson 1984). Tanaka et al. (2013) found enhanced bottom dissipation at the shelf break of the Bering Sea due to D1 trapped waves with bottom-intensified velocities, which contributed to the nutrient supply and productivity of the shelf. Irreversible mixing from shear instabilities can occur when the gradient Richardson number, $\mathrm{Ri}=N^{2} /\|\partial \mathbf{u} / \partial z\|^{2}$, is less than a critical threshold of 0.25 (e.g., Ivey et al. 2018). We quantified this parameter for the mode-one scenarios (shown in Figs. 11 and 12), using the background density to characterize $N^{2}$, the D1 velocity for $\|\partial \mathbf{u} / \partial z\|^{2}$, and scaled to a CTW amplitude of $0.08 \mathrm{~m} \mathrm{~s}^{-1}$. For all scenarios, $\mathrm{Ri} \gg 10$ on the shelf (not shown), due to the small vertical gradients in the horizontal velocity $(\|\partial \mathbf{u} / \partial z\|)$ that were $\mathscr{O}\left(1 \times 10^{-4}\right) \mathrm{s}^{-1}$ as compared to $N$ with $\mathscr{O}\left(1 \times 10^{-2}\right) \mathrm{s}^{-1}$. Even when we included the background alongshore current in our calculations for $\|\partial \mathbf{u} / \partial z\|^{2}$, our estimated Ri $\gg 10$. These values of $\mathrm{Ri}$ are consistent with the concept that CTWs become increasingly barotropic in their modal structure as the water depth decreases (Huthnance 1978), resulting in small estimates of $\|\partial \mathbf{u} / \partial z\|$ and large estimates for $\mathrm{Ri}$ on the shelf. We conclude that CTWs with thermocline-intensified velocity in isolation are unlikely to cause significant turbulent mixing; however, mixing could occur if thermocline-intensified CTWs interact with waves at other frequencies.

\section{Summary and conclusions}

The wave field on the Tasmanian eastern continental shelf includes motion at the diurnal (D1), near-inertial and semidiurnal frequencies. The near-inertial and D1 signals were the most energetic of the three frequencies. We analyze the near-inertial band of variability in a separate manuscript (Schlosser et al. 2018, manuscript submitted to J. Phys. Oceanogr.) and here we have focused on the dynamics of the D1 frequency wave. The D1 tide is subinertial at this latitude, and we conclude that the observed D1 motion was associated with coastaltrapped waves (CTWs). These waves had large velocities that varied over time with the varying stratification and background current. Using a two-dimensional linear CTW solution we characterized the observed D1 velocity as a superposition of a mode-zero and mode-one CTW, where mode one dominates over mode zero. Both the observed and mode-one velocities were intensified within the thermocline. A more strongly stratified thermocline and/or a deeper thermocline (up to the shelfbreak depth) led to larger near-thermocline velocities in both our observations and the mode-one solution. There have been limited observations of subinertial trapped waves being affected by a thermocline, but given D1 trapped waves with a large signal near the thermocline have also been observed by Freeland (1988) to the southeast of Australia ( $4^{\circ}-9^{\circ}$ north of our sampled transect), and by Mihanović et al. (2009) in the Adriatic Sea, our observations and findings are likely applicable to other regions.

We observed both the CTW modal structure and amplitude changing with the background current and stratification. We highlight that the baroclinic and temporally varying East Australian Current Extension may have influenced the generation of the observed D1 CTW. Here we have focused on elucidating the observed changes in the D1 velocity structure, and we find the distribution of energy over the shelf and slope was dependent on the local stratification, including the strength and position of the thermocline, and the background current.

Within the top and bottom Ekman layer regions on the shelf, the observed velocity phase was inconsistent with an alongshore propagating CTW. Also, within the bottom Ekman layer the linear CTW solution predicted intensified bottom velocities when we observed the opposite. The surface and bottom Ekman layers were thereby not consistent with an alongshore propagating linear CTW, likely due to, for example, bottom friction, the local wind stress, and Ekman veering. We advise caution when using the linear CTW solution on the shelf as the boundary dynamics are not well represented.

Acknowledgments. An Australian Research Council Discovery Project (DP 140101322), and a UWA Research Collaboration Award funded this work. T. L. Schlosser acknowledges the support of an Australian Government Research Training Program (RTP) Scholarship. We thank the crew, volunteers and scientists who aided in the field data collection aboard the R/V Revelle, which was funded by the National Science Foundation (OCE-1129763). 
The continental slope moorings, T4 (M32) and T3 (M44), were also funded by the National Science Foundation (OCE-1129763) and were conceived, planned, and executed by Matthew Alford, Jennifer Mackinnon, Jonathan Nash, Harper Simmons, and Gunnar Voet. We also thank Harper Simmons for the combined R/V Revelle multibeam and Geoscience Australia bathymetry used in this study. We thank the two anonymous reviewers whose comments improved this work.

\section{REFERENCES}

Alessi, C. A., and Coauthors, 1985: CODE-2: Moored array and large-scale data report. CODE Tech. Rep. 38/WHOI Tech. Rep. 85-35, 234 pp., https://doi.org/10.1575/1912/1641.

Alford, M. H., and M. Whitmont, 2007: Seasonal and spatial variability of near-inertial kinetic energy from historical moored velocity records. J. Phys. Oceanogr., 37, 2022-2037, https:// doi.org/10.1175/JPO3106.1.

_ J. A. MacKinnon, H. L. Simmons, and J. D. Nash, 2016: Nearinertial internal gravity waves in the ocean. Annu. Rev. Mar. Sci., 8, 95-123, https://doi.org/10.1146/annurev-marine-010814015746.

Bluteau, C. E., S.-L. Smith, G. N. Ivey, T. L. Schlosser, and N. L. Jones, 2016: Assessing the relationship between bed shear stress estimates and observations of sediment resuspension in the ocean. 20th Australasian Fluid Mechanics Conf., Perth, Australia, Australasian Fluid Mechanics Society, 473, https:/ people.eng.unimelb.edu.au/imarusic/proceedings/20/473\% 20Paper.pdf.

Boettger, D., R. Robertson, and L. Rainville, 2015: Characterizing the semidiurnal internal tide off Tasmania using glider data. J. Geophys. Res. Oceans, 120, 3730-3746, https://doi.org/ 10.1002/2015JC010711.

Brink, K. H., 2006: Coastal-trapped waves with finite bottom friction. Dyn. Atmos. Oceans, 41, 172-190, https://doi.org/10.1016/ j.dynatmoce.2006.05.001.

_ 2018: Stable coastal-trapped waves with stratification, topography and mean flow. Woods Hole Open Access Server, https://doi.org/10.1575/1912/10527.

— transport. Part II: Oscillating flow. J. Phys. Oceanogr., 40, 636-655, https://doi.org/10.1175/2009JPO4267.1.

Cartwright, D. E., J. M. Huthnance, R. Spencer, and J. M. Vassie, 1980: On the St Kilda shelf tidal regime. Deep-Sea Res., 27A, 61-70, https://doi.org/10.1016/0198-0149(80)90072-2.

Church, J. A., and H. J. Freeland, 1987: The energy source for the coastal-trapped waves in the Australian Coastal Experiment Region. J. Phys. Oceanogr., 17, 289-300, https://doi.org/ 10.1175/1520-0485(1987)017<0289:TESFTC > 2.0.CO;2.

Codiga, D. L., and C. C. Eriksen, 1997: Observations of lowfrequency circulation and amplified subinertial tidal currents at Cobb Seamount. J. Geophys. Res., 102, 22 993-23007, https://doi.org/10.1029/97JC01451.

— D. P. Renouard, and A. M. Fincham, 1999: Experiments on waves trapped over the continental slope and shelf in a continuously stratified rotating ocean, and their incidence on a canyon. J. Mar. Res., 57, 585-612, https://doi.org/10.1357/ 002224099321549602.

Crawford, W. R., and R. E. Thomson, 1984: Diurnal-period continental shelf waves along Vancouver Island: A comparison of observations with theoretical models. J. Phys. Oceanogr., 14, 1629-1646, https://doi.org/10.1175/1520-0485(1984)014<1629: DPCSWA $>2.0 . \mathrm{CO} ; 2$.

Cresswell, G., 2000: Currents of the continental shelf and upper slope of Tasmania. Pap. Proc. Roy. Soc. Tasmania, 133 (3), 21-30, https://doi.org/10.26749/rstpp.133.3.21.

Cushman-Roisin, B., and B. Jean-Marie, 2011: Introduction to Geophysical Fluid Dynamics: Physical and Numerical Aspects. 2nd ed., International Geophysics Series, Vol. 101, Academic Press, $875 \mathrm{pp}$.

Falahat, S., and J. Nycander, 2015: On the generation of bottomtrapped internal tides. J. Phys. Oceanogr., 45, 526-545, https:// doi.org/10.1175/JPO-D-14-0081.1.

Freeland, H. J., 1988: Diurnal coastal-trapped waves on the east Australian continental shelf. J. Phys. Oceanogr., 18, 690694, https://doi.org/10.1175/1520-0485(1988)018<0690: DCTWOT $>2.0 . \mathrm{CO} ; 2$.

Gill, A. E., 1982: Atmosphere-Ocean Dynamics. International Geophysics Series, Vol. 30, Academic Press, 662 pp.

Goring, D. G., and V. I. Nikora, 2002: Despiking acoustic Doppler velocimeter data. J. Hydraul. Eng., 128, 117-126, https:// doi.org/10.1061/(ASCE)0733-9429(2002)128:1(117).

Huthnance, J. M., 1978: On coastal trapped waves: Analysis and numerical calculation by inverse iteration. J. Phys. Oceanogr., 8, 74-92, https://doi.org/10.1175/1520-0485(1978)008<0074: OCTWAA $>2.0 . \mathrm{CO} ; 2$.

Ivey, G. N., C. E. Bluteau, and N. L. Jones, 2018: Quantifying diapycnal mixing in an energetic ocean. J. Geophys. Res. Oceans, 123, 346-357, https://doi.org/10.1002/2017JC013242.

Johnston, T. S., and D. L. Rudnick, 2015: Trapped diurnal internal tides, propagating semidiurnal internal tides, and mixing estimates in the California Current System from sustained glider observations, 2006-2012. Deep-Sea Res. II, 112, 61-78, https:// doi.org/10.1016/j.dsr2.2014.03.009.

Klymak, J. M., H. L. Simmons, D. Braznikov, S. Kelly, J. A. MacKinnon, M. H. Alford, R. Pinkel, and J. D. Nash, 2016: Reflection of linear internal tides from realistic topography: The Tasman continental slope. J. Phys. Oceanogr., 46, 33213337, https://doi.org/10.1175/JPO-D-16-0061.1.

Leblond, P. H., and L. A. Mysak, 1978: Waves in the Ocean. Elsevier, 602 pp.

Lilly, J. M., 2017: jLab: A data analysis package for Matlab, version 1.6.3. http://www.jmlilly.net/jmlsoft.html.

Mihanović, H., M. Orlić, and Z. Pasarić, 2009: Diurnal thermocline oscillations driven by tidal flow around an island in the Middle Adriatic. J. Mar. Syst., 78 (Suppl.), S157-S168, https://doi.org/ 10.1016/j.jmarsys.2009.01.021.

Murphy, A. H., 1988: Skill scores based on the mean square error and their relationships to the correlation coefficient. Mon. Wea. Rev., 116, 2417-2424, https://doi.org/10.1175/15200493(1988)116<2417:SSBOTM > 2.0.CO;2.

Musgrave, R. C., J. A. MacKinnon, R. Pinkel, A. F. Waterhouse, and J. D. Nash, 2016: Tidally driven processes leading to nearfield turbulence in a channel at the crest of the mendocino escarpment. J. Phys. Oceanogr., 46, 1137-1155, https://doi.org/ 10.1175/JPO-D-15-0021.1.

,,,,,----- and S. M. Kelly, 2017: The influence of subinertial internal tides on near-topographic turbulence at the mendocino ridge: Observations and modeling. J. Phys. Oceanogr., 47, 2139-2157, https://doi.org/10.1175/JPO-D-16-0278.1.

Mysak, L. A., 1980: Topographical trapped waves. Annu. Rev. Fluid Mech., 12, 45-76, https://doi.org/10.1146/ annurev.fl.12.010180.000401. 
Oliver, E. C. J., M. Herzfeld, and N. J. Holbrook, 2016: Modelling the shelf circulation off eastern Tasmania. Cont. Shelf Res., 130, 14-33, https://doi.org/10.1016/j.csr.2016.10.005.

Pinkel, R., M. A. Goldin, J. A. Smith, O. M. Sun, A. A. Aja, M. N. Bui, and T. Hughen, 2011: The Wirewalker: A vertically profiling instrument carrier powered by ocean waves. J. Atmos. Oceanic Technol., 28, 426-435, https://doi.org/ 10.1175/2010JTECHO805.1.

_- and Coauthors, 2015: Breaking internal tides keep the ocean in balance. Eos, Trans. Amer. Geophys. Union, 96, 1-5, https:// doi.org/10.1029/2015EO039555.

Rainville, L., and R. Pinkel, 2001: Wirewalker: An autonomous wave-powered vertical profiler. J. Atmos. Oceanic Technol., 18, 1048-1051, https://doi.org/10.1175/1520-0426(2001)018<1048: WAAWPV $>2.0$.CO;2.

Rayson, M. D., G. N. Ivey, N. L. Jones, R. J. Lowe, G. W. Wake, and J. D. McConochie, 2015: Near-inertial ocean response to tropical cyclone forcing on the Australian North-West Shelf. J. Geophys. Res. Oceans, 120, 7722-7751, https://doi.org/ 10.1002/2015JC010868.

Rhines, P., 1970: Edge-, bottom-, and Rossby waves in a rotating stratified fluid. Geophys. Fluid Dyn., 1, 273-302, https:// doi.org/10.1080/03091927009365776.

Ridgway, K. R., 2007: Long-term trend and decadal variability of the southward penetration of the East Australian Current. Geophys. Res. Lett., 34, L13613, https://doi.org/10.1029/2007GL030393.

Shroyer, E. L., J. N. Moum, and J. D. Nash, 2011: Nonlinear internal waves over New Jersey's continental shelf.
J. Geophys. Res., 116, C03022, https://doi.org/10.1029/ 2010JC006332.

Simmons, H. L., R. W. Hallberg, and B. K. Arbic, 2004: Internal wave generation in a global baroclinic tide model. Deep-Sea Res. II, 51, 3043-3068, https://doi.org/10.1016/ j.dsr2.2004.09.015.

Smith, S. D., 1988: Coefficients for sea surface wind stress, heat flux, and wind profiles as a function of wind speed and temperature. J. Geophys. Res., 93, 15 467-15 472, https://doi.org/10.1029/ JC093iC12p15467.

Stashchuk, N., and V. Vlasenko, 2017: Bottom trapped internal waves over the Malin Sea continental slope. Deep-Sea Res. I, 119, 68-80, https://doi.org/10.1016/j.dsr.2016.11.007.

Tanaka, T., I. Yasuda, Y. Tanaka, and G. S. Carter, 2013: Numerical study on tidal mixing along the shelf break in the Green Belt in the southeastern Bering Sea.J. Geophys. Res. Oceans, 118, 6525-6542, https://doi.org/10.1002/2013JC009113.

Waterhouse, A. F., J. A. Mackinnon, R. C. Musgrave, S. M. Kelly, A. Pickering, and J. Nash, 2017: Internal tide convergence and mixing in a submarine canyon. J. Phys. Oceanogr., 47, 303-322, https://doi.org/10.1175/JPO-D-16-0073.1.

_ , and Coauthors, 2018: Observations of the Tasman Sea internal tide beam. J. Phys. Oceanogr., 48, 1283-1297, https:// doi.org/10.1175/JPO-D-17-0116.1.

Wilkin, J. L., and D. C. Chapman, 1990: Scattering of coastaltrapped waves by irregularities in coastline and topography. J. Phys. Oceanogr., 20, 396-421, https://doi.org/10.1175/15200485(1990)020<0396:SOCTWB >2.0.CO;2. 